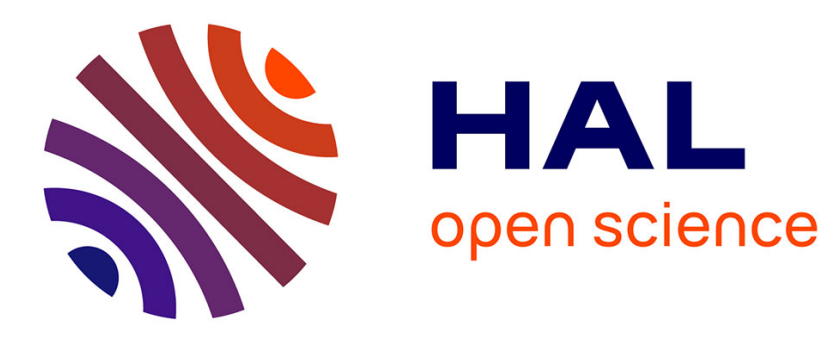

\title{
Gamma rays as an innovative tool for synthesizing conducting copolymers with improved properties
}

Teseer Bahry, Benazir Khurshid, Yamina Chouli, Souad Abou Zeid, Cyrille

Sollogoub, Matthieu Gervais, Thanh-Tuân Bui, Fabrice Goubard, Samy

Remita

\section{To cite this version:}

Teseer Bahry, Benazir Khurshid, Yamina Chouli, Souad Abou Zeid, Cyrille Sollogoub, et al.. Gamma rays as an innovative tool for synthesizing conducting copolymers with improved properties. New Journal of Chemistry, 2021, 45 (29), pp.13142-13157. 10.1039/d1nj02300d . hal-03338213

\section{HAL Id: hal-03338213 \\ https://hal.science/hal-03338213}

Submitted on 8 Sep 2021

HAL is a multi-disciplinary open access archive for the deposit and dissemination of scientific research documents, whether they are published or not. The documents may come from teaching and research institutions in France or abroad, or from public or private research centers.
L'archive ouverte pluridisciplinaire HAL, est destinée au dépôt et à la diffusion de documents scientifiques de niveau recherche, publiés ou non, émanant des établissements d'enseignement et de recherche français ou étrangers, des laboratoires publics ou privés. 


\title{
Gamma rays as an innovative tool for synthesizing conducting copolymers with improved properties $\dagger$
}

\author{
Teseer Bahry, ${ }^{a}$ Benazir Khurshid, ${ }^{a}$ Yamina Chouli, ${ }^{a}$ Souad Abou Zeid, ${ }^{a}$ \\ Cyrille Sollogoub, ${ }^{b}$ Matthieu Gervais, (D) ${ }^{b}$ Thanh-Tuân Bui, (D) ${ }^{c}$ Fabrice Goubard ${ }^{c}$ \\ and Samy Remita (D) *ad
}

\begin{abstract}
In the present study, copolymers of pyrrole (Py) with different co-monomers (thiophene derivatives) were originally polymerized through two radiolytic approaches: water radiolysis and dichloromethane radiolysis. This method can be easily controlled and is adaptable. The main objective of copolymerization is to increase the solubility and processability of polypyrrole (PPy). The synthesis of copolymers was validated by UV-Vis absorption spectroscopy that indicates monomers' quantitative consumption and by ATR-FTIR that validates their chemical composition. Scanning electron microscopy (SEM) and cryogenic transmission electron microscopy (Cryo-TEM) were used to check the morphology and topography of the synthesized copolymers of Py and to compare them with their respective homopolymers. Additionally, a comparative study of thermal behavior and molecular weight distribution of copolymers with their homopolymers was performed using thermogravimetric analysis (TGA) and size exclusion chromatography (SEC), respectively. Finally, conductivity and electrochemical measurements were performed. The results showed the successful synthesis of copolymers of Py by this novel radiolytic method with changes in their morphologies and physicochemical properties with respect to the homopolymers. The present work definitely validates radiation chemistry as an alternative approach to synthesize conducting copolymers.
\end{abstract}

Conducting polymers (CPs) with desired properties for different applications have attracted the attention of many scientists in order to develop more and more processable, advantageous, and cheap CPs. ${ }^{1,2}$ Generally, these CPs are semiconducting materials in the neutral state and exhibit metal-like conductive properties upon doping. ${ }^{3}$ The significant advantage of these organic conducting polymers over inorganic semiconductors is their long-range order and ease of modification. ${ }^{4}$ The unique combination of the excellent mechanical properties of polymers with the electronic properties of organic semiconductors

\footnotetext{
${ }^{a}$ Institut de Chimie Physique, ICP, UMR 8000, CNRS, Université Paris-Saclay, Bâtiment 349, Campus d'Orsay, 15 Avenue Jean Perrin, 91405, Orsay Cedex, France.E-mail: samy.remita@universite-paris-saclay.fr

${ }^{b}$ Laboratoire PIMM, Arts et Métiers Institute of Technology, CNRS, CNAM, Hesam Université, F-75013, Paris Cedex, France

${ }^{c}$ CY Cergy Paris Université, LPPI, F95000, Cergy, France

${ }^{d}$ Département Chimie Vivant Santé, EPN 7, Conservatoire National des Arts et Métiers, CNAM, 292 Rue Saint-Martin, 75141, Paris Cedex 03, France

† Electronic supplementary information (ESI) available. See DOI: 10.1039/ d1nj02300d
}

makes CPs more attractive than conventional conducting materials.

Among all CPs, polypyrrole (PPy) is extensively studied due to its high conductivity, stability in the oxidized form, and low-cost monomers. ${ }^{5}$ It is one of the heterocyclic conducting polymers which have drawn the interest of many scientists due to its oxidizability and solubility in water that makes it distinguishable and advantageous compared to other conducting polymers. Moreover, it is thermally stable, even up to $200{ }^{\circ} \mathrm{C}$. Its characteristic colours depend on the degree of oxidation, i.e., from yellow to black according to the increasing degree of oxidation. ${ }^{6}$ Besides, the susceptibility of PPy towards structural distortion makes it useful for electrochromic applications. ${ }^{7}$

Nevertheless, the low processability of PPy in organic solvents and low electrochemical and environmental stability (especially in oxidative atmospheres) demand a more stable conducting polymer for use in many technological applications. ${ }^{8}$ In the literature, many studies have been conducted to increase the processability and stability of PPy. $N$-substitution with different polypyrrole functionalities leads to the reduction of environmental oxidation and to the increase of solubility, making it more processable. ${ }^{9}$ Moreover, 3,4 substitution of polypyrrole is extensively studied. 
It prevents $\alpha-\beta$ coupling during polymerization which is known to decrease the conjugation length and solubility. ${ }^{10,11}$

Above all, copolymerization is a simple and common method to modify the properties of PPy by combining the properties of its co-monomers. ${ }^{12}$ For example, Tewari et al. synthesized PPy/PEDOT copolymers of better conductivity by an enzyme catalysis method, ${ }^{13}$ whereas synthesis of a copolymer of poly(vinyl alcohol) with thiophene side groups and polypyrrole was performed by Sahmetlioglu et al. to obtain more conductive and thermally stable polymers. ${ }^{14}$

The use of gamma rays to generate free radicals to synthesize CPs appears to be a suitable method for eliminating the use of chemical oxidants and catalysts. ${ }^{15,16}$ Free radicals are intermediates in many chemical reactions and are important in polymerization and many other chemical processes. ${ }^{17}$ The use of radiation chemistry to generate free radical-induced polymerization has been developed as an alternative method to synthesize conducting polymers. Early studies demonstrated that $\mathrm{HO}^{\bullet}$ radicals in situ produced in a medium during water radiolysis efficiently polymerized some organic monomers, such as 3,4-ethylenedioxythiophene (EDOT) and pyrrole (Py), dissolved in aqueous solutions. ${ }^{15,18,19}$ Published studies in later times investigated the use of other species such as $\mathrm{N}_{3}{ }^{\circ}, \mathrm{SO}_{4}{ }^{-}, \mathrm{e}_{\mathrm{aq}}{ }^{-}$and $\mathrm{Cl}_{2}{ }^{--}$by adjusting the irradiation conditions (additive of salts or radical scavengers, adjusting the $\mathrm{pH}$ and changing the atmosphere) in order to polymerize EDOT monomers. ${ }^{16,20-22}$ Beyond the use of water radiolysis, dichloromethane (DCM) radiolysis has also been further exploited to synthesize, starting from thiophene derivatives (3,4ethylenedioxythiophene (EDOT), 3-thiophene acetic acid (TAA) and 3-hexylthiophene (3HT)), new conducting polymers with improved optical and electronic properties. ${ }^{23-25}$

These radiolytic methods have opened up new possibilities to develop conducting homopolymers (PPy, PEDOT, PTAA and P3HT) either in water or DCM, with tuned optical/electronic properties and controlled structures. When compared with conventional chemical methodologies, radiation chemistry enabled the improvement of the stability, processability and properties of PPy homopolymers. Indeed, radiosynthesized PPys were found to be more hydrophilic and less polydisperse than chemically synthesized PPys. Also, radiosynthesized PPys were found to exhibit very good long-term stability in air and an electrical conductivity five times larger than that of chemically synthesized PPys. ${ }^{19}$ Moreover, a recent study highlighted the paramount performance of gamma-synthesized PPys in the photocatalytic degradation of organic pollutants under UV as well as visible light. ${ }^{26}$

The main objective of the present work is to use the radiolytic method to synthesize, both in water and in DCM solvent, pyrrole copolymers with different co-monomers in order to enhance the properties and processability of PPy. The candidate co-monomers are TAA, EDOT and 3HT, and the copolymers to synthesize are PPy/PTAA, PPy/PEDOT and $\mathrm{PPy} / \mathrm{P} 3 \mathrm{HT}$, respectively (Scheme 1). The objective of this work is also to study the structural, morphological, spectral, thermal, conductive and electrochemical properties of these copolymers and to compare them with those of PPy, PTAA, PEDOT and

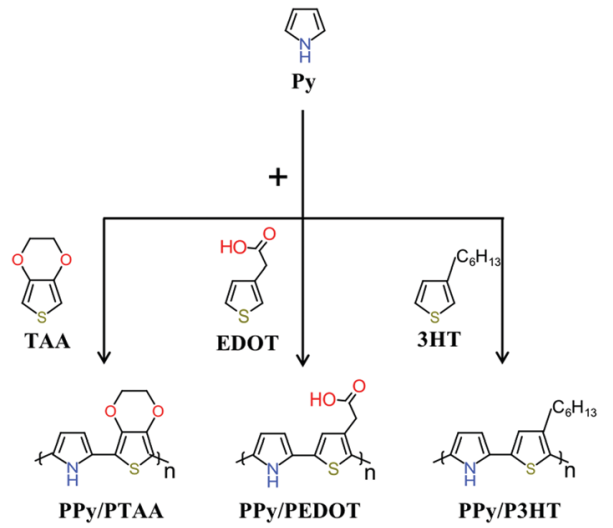

Scheme 1 Structures of pyrrole copolymers synthesized in this work.

P3HT homopolymers. While most of the homopolymer radiosynthesis methods have already been described in our previous studies, the synthesis of PPy in DCM as well as that of all copolymers described in the present work is totally new and original. To optimize the synthesis conditions, enhance the yield of polymerization and produce betternanostructured copolymers, both water and DCM are used as solvents, whereas radiolysis is achieved under different environments such as $\mathrm{O}_{2}, \mathrm{~N}_{2}$ and $\mathrm{N}_{2} \mathrm{O}$, as described in the next section.

For pedagogical purposes, the present work mainly focuses on the results obtained with PPy/PTAA copolymers, comparing them with those obtained with PPy and PTAA homopolymers. Findings concerning the other copolymers, namely, PPy/PEDOT and $\mathrm{PPy} / \mathrm{P} 3 \mathrm{HT}$, together with their corresponding homopolymers, are displayed in the ESI. $\dagger$

\section{Materials and methods}

\subsection{Reagents and solvents}

Pyrrole (Py), 3,4-ethylenedioxythiophene (EDOT), 3-thiophene acetic acid (TAA) and 3-hexylthiophene (3HT) used as monomers were purchased from Sigma-Aldrich. Distilled water (Millipore system $\left.18.2 \mathrm{M} \Omega \mathrm{cm}^{-1}\right)$ and dichloromethane (DCM) $(\geq 99.9 \%$, from Sigma Aldrich) were used as the solvents for gammaradiolysis. Nitrous oxide $\left(\mathrm{N}_{2} \mathrm{O}\right)$, nitrogen $\left(\mathrm{N}_{2}\right)$ and oxygen $\left(\mathrm{O}_{2}\right)$ gases (from Air Liquid Co. with purity $99.99 \%$ ) were respectively used to saturate aqueous or dichloromethane solutions before $\gamma$ irradiations. Ethanol and acetone ( $\geq 99 \%$, from VWR chemicals) were used for cleaning purposes. Tetrahydrofuran (THF) ( $\geq 99.9 \%$, from Sigma Aldrich) was used to solubilize the radio-synthesized polymers after solvent evaporation. For electrochemical measurements, tetrabutylammonium perchlorate (TBA$\left.\mathrm{ClO}_{4}\right)(\geq 98 \%$, from Sigma Aldrich) was used as an electrolyte by dissolving it in acetonitrile (purchased from VWE chemicals). Nitrosyl tetrafluoroborate $\left(\mathrm{NOBF}_{4}\right)(\geq 95 \%$, purchased from Sigma-Aldrich) dissolved in acetonitrile was used as a dopant during electrical conductivity measurements. All experiments were performed at room temperature. 


\subsection{Solution preparation and irradiation}

In order to synthesize homopolymers, aqueous or DCM solutions containing $10 \mathrm{mM}$ monomers (Py, TAA, EDOT or 3HT) were prepared. Note that $3 \mathrm{HT}$, which is a hydrophobic monomer, is not soluble in water. For the synthesis of copolymers, aqueous or DCM solutions containing $5 \mathrm{mM}$ Py and $5 \mathrm{mM}$ co-monomer (TAA, EDOT or $3 \mathrm{HT}$ ) (10 $\mathrm{mM}$ total monomer concentration) were also prepared (Table SI1, ESI $\dagger$ ). All the monomer solutions were stirred properly and all the UV-Vis absorption spectra were recorded before irradiation (Fig. 1 and Fig. SI1, ESI $\dagger$ ). After that, the aqueous solutions were all degassed with $\mathrm{N}_{2} \mathrm{O}$, while the DCM solutions were degassed with $\mathrm{N}_{2}$ except those containing 3HT which were degassed with $\mathrm{O}_{2}$ (Table SI1, ESI $\dagger$ ). After degassing for 25 minutes, all the monomer solutions were irradiated at $36 \mathrm{kGy}$ at a dose rate of about $4 \mathrm{kGy} \mathrm{h}^{-1}$. The irradiations were performed with a ${ }^{60} \mathrm{Co}$ panoramic $\gamma$-ray source of 3000 Curie at ICP, Université Paris-Saclay.

In addition to synthesising homopolymers in water $\left(\mathrm{PPy}_{\mathrm{H}_{2} \mathrm{O}}\right.$, PTAA $_{\mathrm{H}_{2} \mathrm{O}}$ and PEDOT $_{\mathrm{H}_{2} \mathrm{O}}$ ) and in DCM (PPy DCM, PTAA $_{\text {DCM }}$, PEDOT $_{\text {DCM }}$ and $\mathrm{P}_{3} \mathrm{HT}_{\mathrm{DCM}}$ ), the challenge of the present work was to originally synthesize, by means of gamma-radiolysis, copolymers either in water $\left(\mathrm{PPy} / \mathrm{PTAA}_{\mathrm{H}_{2} \mathrm{O}}\right.$ and PPy/PEDOT $\left.\mathrm{H}_{2} \mathrm{O}\right)$ or in DCM solvent (PPy/PTAA ${ }_{\mathrm{DCM}}, \mathrm{PPy}_{\mathrm{PEDOT}} \mathrm{PCM}_{\mathrm{P}}$ and PPy/ $\left.\mathrm{P} 3 \mathrm{HT}_{\mathrm{DCM}}\right)$ (Table SI1, ESI $\dagger$ ).

\subsection{Solvent radiolysis}

The main idea of synthesizing homopolymers and copolymers using radiolytic methodology is that solvent radiolysis generates oxidizing species which induce monomer (together with comonomer) oxidation and thus polymerization and copolymerization either in water or DCM. Importantly, the produced oxidizing radicals depend on the solvent and the environment under which radiolysis is conducted. Besides, the hydrophilicity and morphology of CPs change on changing the radicals involved in polymerization.

2.3.1. Water radiolysis under $\mathbf{N}_{2} \mathbf{O}$. It is well-known that the $\gamma$-ray irradiation of deoxygenated aqueous solutions at neutral $\mathrm{pH}$ generates the following various radiolytic species: ${ }^{27-29}$

$$
\mathrm{H}_{2} \mathrm{O} \rightarrow \mathrm{e}_{\mathrm{aq}}{ }^{-}, \mathrm{H}_{3} \mathrm{O}^{+}, \mathrm{H}^{\bullet}, \mathrm{HO}^{\bullet}, \mathrm{H}_{2} \mathrm{O}_{2}, \mathrm{H}_{2}
$$

Also, the radiolytic yields of formation of the different radical species are well known: $G_{\mathrm{HO}^{\bullet}}=2.8 \times 10^{-7} \mathrm{~mol} \mathrm{~J}^{-1}, G_{\text {eaq- }}=2.8 \times$ $10^{-7} \mathrm{~mol} \mathrm{~J}^{-1}$ and $G_{\mathrm{H}^{\bullet}}=0.6 \times 10^{-7} \mathrm{~mol} \mathrm{~J}^{-1} \cdot \cdot^{27-30}$
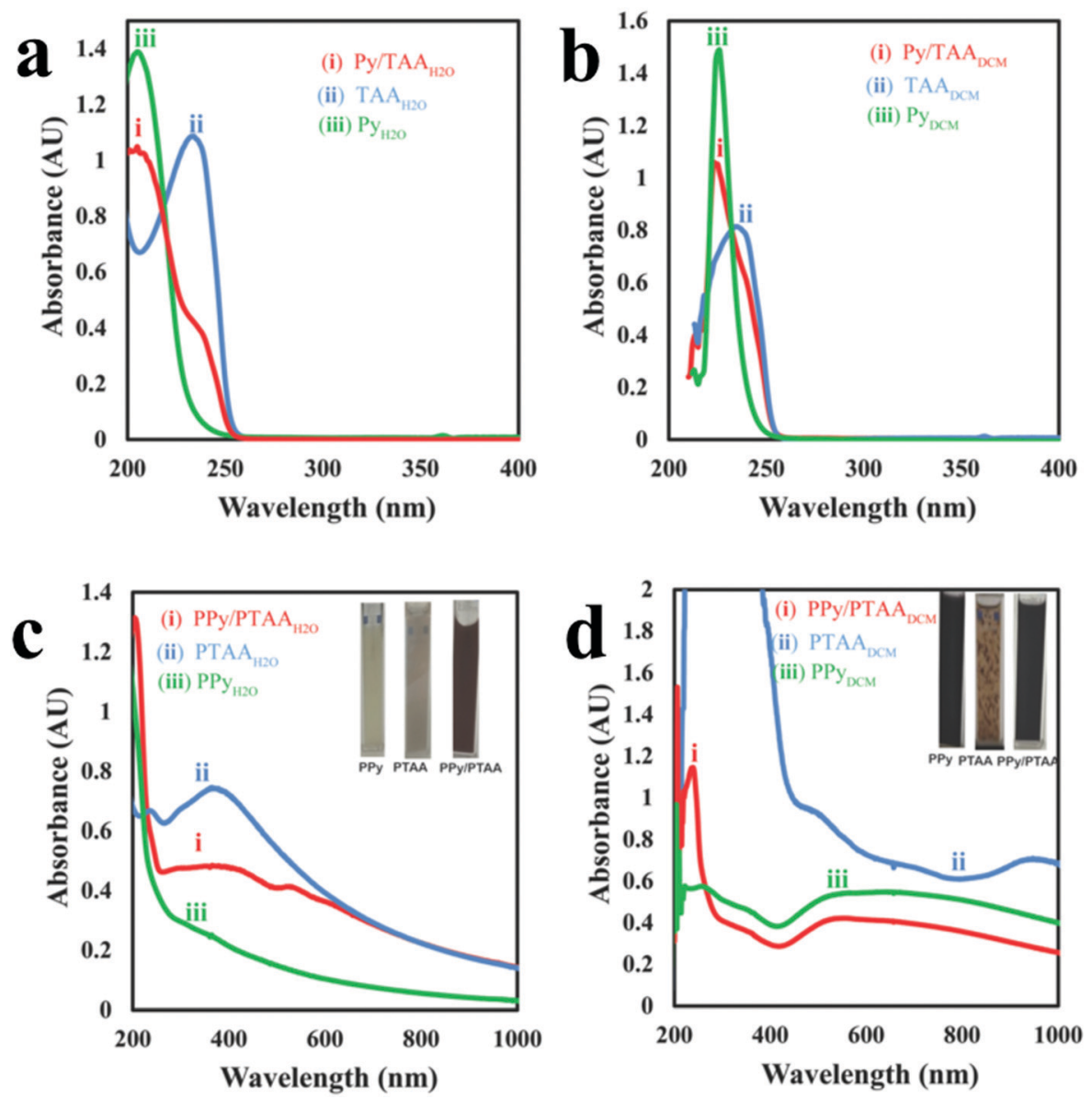

Fig. 1 UV-Vis absorption spectra of (a) Py, TAA and Py/TAA aqueous solutions, (b) Py, TAA, and Py/TAA dichloromethane (DCM) solutions, (c) aqueous solutions of Py, TAA and Py/TAA irradiated at 36 kGy and (d) DCM solutions of Py, TAA and Py/TAA irradiated at 36 kGy. Insets: Photographs of polymer suspensions obtained after irradiation. The total concentration of the monomers was $10 \mathrm{mM}$ in all the cases. The optical path length was $0.2 \mathrm{~cm}$ and the reference was a pure solvent. All the solutions were diluted 10 times except PTAA in DCM which was concentrated 10 times. 
In the presence of $\mathrm{N}_{2} \mathrm{O}$, the solvated electrons, $\mathrm{e}_{\mathrm{aq}}{ }^{-}$, produced in eqn (1) can be efficiently scavenged and converted into $\mathrm{HO}^{\bullet}$ according to: ${ }^{27,28}$

$$
\mathrm{e}_{\mathrm{aq}}{ }^{-}+\mathrm{N}_{2} \mathrm{O}+\mathrm{H}_{2} \mathrm{O} \rightarrow \mathrm{HO}^{\bullet}+\mathrm{HO}^{-}+\mathrm{N}_{2}
$$

Thus, in a neutral aqueous medium under $\mathrm{N}_{2} \mathrm{O}$, the radiolytic yield of the formation of $\mathrm{HO}^{\bullet}$ amounts to $G\left(\mathrm{HO}^{\bullet}\right)=$ $5.6 \times 10^{-7} \mathrm{~mol} \mathrm{~J}^{-1}$.

Contrary to $\mathrm{H}^{\bullet}$ radicals, $\mathrm{HO}^{\bullet}$ radicals are known as strong oxidizing species that have been shown to completely oxidize organic monomers (namely, Py, TAA and EDOT) leading to the quantitative production of $\mathrm{PPy}_{\mathrm{H}_{2} \mathrm{O}}, \mathrm{PTAA}_{\mathrm{H}_{2} \mathrm{O}}$ and $\mathrm{PEDOT}_{\mathrm{H}_{2} \mathrm{O}}$ conducting polymers by water radiolysis. ${ }^{15,18,19}$ As a consequence, $G\left(\mathrm{HO}^{\bullet}\right)$ also corresponds to the yield of monomer oxidation in water under $\mathrm{N}_{2} \mathrm{O}$.

Thanks to the pulse radiolysis study, the radiation-induced growth mechanism of CPs was shown to proceed through a step-by-step mechanism instead of a chain mechanism. ${ }^{18}$ Therefore, as highlighted in our previous studies, ${ }^{15,18,19,23-25}$ the theoretical irradiation dose, $D_{\max }$ (expressed in Gy, 1 Gy corresponding to $1 \mathrm{~J} \mathrm{~kg}^{-1}$ ), needed for the quantitative formation of CPs in aqueous solutions is twice the dose necessary for the total oxidation of monomers (by $\mathrm{HO}^{\bullet}$ radicals) and can be calculated as follows:

$$
D_{\max }(\mathrm{Gy})=\frac{2 \times[\text { Monomers }]\left(\mathrm{mol} \mathrm{L}^{-1}\right)}{G\left(\mathrm{HO}^{\bullet}\right)\left(\mathrm{mol} \mathrm{J}^{-1}\right) \times d\left(\mathrm{~kg} \mathrm{~L}^{-1}\right)}
$$

where [Monomers] is the initial concentration of monomers (Py, TAA or EDOT) in water and $d$ is the water density $\left(d=1 \mathrm{~kg} \mathrm{~L}^{-1}\right)$.

As a consequence, starting from $10 \mathrm{mM}$ monomers (with or without co-monomers) dissolved in water under $\mathrm{N}_{2} \mathrm{O}$, the dose, $D_{\text {max }}$, needed for the quantitative production of homopolymers $\left(\mathrm{PPy}_{\mathrm{H}_{2} \mathrm{O}}, \mathrm{PTAA}_{\mathrm{H}_{2} \mathrm{O}}\right.$ and PEDOT $\mathrm{H}_{2} \mathrm{O}$ ) or copolymers (PPy/PTAA $\mathrm{H}_{2} \mathrm{O}$ and $\mathrm{PPy} / \mathrm{PEDOT}_{\mathrm{H}_{2} \mathrm{O}}$ ) is $36 \mathrm{kGy}$ in all cases. As demonstrated in previous studies, increasing the irradiation dose leads to longer polymers. Nevertheless, the longer chain length is in fact obtained at the optimal irradiation dose $D_{\max }$ (36 kGy in water). Indeed, above this radiation dose, overoxidation of polymers leads to degradation and breaking down of polymer chains. $^{23-25}$

2.3.2. Dichloromethane radiolysis under $\mathrm{N}_{2}$ and $\mathbf{O}_{2}$. Dichloromethane (DCM) is one of the most important solvents which can dissolve the majority of organic compounds such as Py, EDOT, TAA and even hydrophobic 3HT monomers. ${ }^{23-25}$

Gamma radiolysis of DCM under an inert atmosphere, such as $\mathrm{N}_{2}$, leads to two oxidizing species, namely, chloromethyl $\left(\mathrm{CH}_{2} \mathrm{Cl}^{\bullet}\right)$ and dichloromethyl $\left(\mathrm{CHCl}_{2}{ }^{\bullet}\right)$ radicals according to: ${ }^{31,32}$

$$
2 \mathrm{CH}_{2} \mathrm{Cl}_{2} \rightarrow \mathrm{CH}_{2} \mathrm{Cl}^{\bullet}+\mathrm{CHCl}_{2}^{\bullet}+\mathrm{HCl}
$$

These radicals were shown to efficiently oxidize organic monomers (such as TAA and EDOT) leading to the quantitative production of the corresponding PTAA $_{\mathrm{DCM}}$ and PEDOT $_{\mathrm{DCM}}$ conducting polymers. ${ }^{23-25}$ Due to the relatively low redox potentials of EDOT and TAA, their yield of oxidation, Gox, in DCM under $\mathrm{N}_{2}$ was found to be $4.1 \times 10^{-7} \mathrm{~mol} \mathrm{~J}^{-1}$. Nevertheless, due to the higher redox potential of $3 \mathrm{HT}$ monomers, their yield of oxidation under $\mathrm{N}_{2}$ was found to be much lower. ${ }^{25}$

In order to promote the oxidation of $3 \mathrm{HT}$ and to successfully produce $\mathrm{P} 3 \mathrm{HT}_{\mathrm{DCM}}$ conducting polymers, DCM radiolysis must be considered under an $\mathrm{O}_{2}$ atmosphere. ${ }^{25}$ Indeed, in the presence of oxygen, ${ }^{31}\left(\mathrm{CH}_{2} \mathrm{Cl}^{\bullet}\right)$ and $\left(\mathrm{CHCl}_{2}{ }^{\bullet}\right)$ radicals are scavenged by $\mathrm{O}_{2}$ molecules leading to the corresponding peroxyl radicals $\mathrm{CH}_{2} \mathrm{ClO}_{2}{ }^{\bullet}$ and $\mathrm{CHCl}_{2} \mathrm{O}_{2}{ }^{\bullet}$ according to: ${ }^{31,33}$

$$
2 \mathrm{CH}_{2} \mathrm{Cl}_{2}+2 \mathrm{O}_{2} \rightarrow \mathrm{CH}_{2} \mathrm{ClO}_{2}^{\bullet}+\mathrm{CHCl}_{2} \mathrm{O}_{2}^{\bullet}+\mathrm{HCl}
$$

Contrary to chloromethyl $\mathrm{CH}_{2} \mathrm{Cl}^{\bullet}$ and dichloromethyl $\mathrm{CHCl}_{2}{ }^{\bullet}$ radicals, peroxyl radicals which are produced under an $\mathrm{O}_{2}$ atmosphere are characterized by very high oxidizing power and were shown to quantitatively oxidize 3HT monomers leading to the formation of $\mathrm{P}_{3} \mathrm{HT}_{\mathrm{DCM}} \mathrm{CPs}{ }^{25,31,33}$ The yield of $3 \mathrm{HT}$ oxidation, Gox, in DCM under $\mathrm{O}_{2}$ was also found to be $4.1 \times 10^{-7} \mathrm{~mol} \mathrm{~J}^{-1} .^{25}$

As highlighted in previous studies, ${ }^{23-25}$ the theoretical irradiation dose, $D_{\max }$, needed for the quantitative formation of CPs in DCM solutions is once again twice the dose necessary for the total oxidation of organic monomers (Py, TAA and EDOT monomers by $\mathrm{CH}_{2} \mathrm{Cl}^{\bullet}$ and $\mathrm{CHCl}_{2}{ }^{\bullet}$ radicals under $\mathrm{N}_{2}$, or $3 \mathrm{HT}$ monomers by $\mathrm{CH}_{2} \mathrm{ClO}_{2}{ }^{\bullet}$ and $\mathrm{CHCl}_{2} \mathrm{O}_{2}{ }^{\bullet}$ radicals under $\mathrm{O}_{2}$ ) and can thus be calculated as follows:

$$
D_{\max }(\mathrm{Gy})=\frac{2 \times[\text { Monomers }]\left(\mathrm{mol} \mathrm{L}^{-1}\right)}{\operatorname{Gox}\left(\mathrm{mol} \mathrm{J}^{-1}\right) \times d^{\prime}\left(\mathrm{kg} \mathrm{L}^{-1}\right)}
$$

where [Monomers] is the initial concentration of monomers (Py, TAA, EDOT and 3HT) in DCM, Gox is the yield of monomer oxidation $\left(4.1 \times 10^{-7} \mathrm{~mol} \mathrm{~J}^{-1}\right.$, for Py, TAA and EDOT under $\mathrm{N}_{2}$ and for $3 \mathrm{HT}$ under $\left.\mathrm{O}_{2}\right)$ and $d^{\prime}$ is the DCM density $\left(d^{\prime}=1.35 \mathrm{~kg} \mathrm{~L}^{-1}\right)$.

As a consequence, starting from $10 \mathrm{mM}$ monomers (with or without co-monomers) dissolved in DCM under $\mathrm{N}_{2}$ or under $\mathrm{O}_{2}$ (when $3 \mathrm{HT}$ is present), the dose, $D_{\max }$, needed for the quantitative production of homopolymers $\left(\mathrm{PPy}_{\mathrm{DCM}}, \mathrm{PTAA}_{\mathrm{DCM}}, \mathrm{PEDOT}_{\mathrm{DCM}}\right.$ and $\mathrm{P} 3 \mathrm{HT}_{\mathrm{DCM}}$ ) or copolymers (PPy/PTAA $\mathrm{DCM}_{\mathrm{D}}, \mathrm{PPy}_{\mathrm{PEDOT}} \mathrm{PCM}_{\mathrm{P}}$ and PPy/ $\left.\mathrm{P} 3 \mathrm{HT}_{\mathrm{DCM}}\right)$ is $36 \mathrm{kGy}$ in all cases. Once again, as demonstrated in previous studies and as already explained, even if increasing the irradiation dose leads to longer polymers, the longer polymer chains are obtained at the optimal irradiation dose $D_{\max }$ (36 kGy in DCM) since overoxidation of polymers leads to breaking down of polymer chains. ${ }^{23-25}$

Note that this dose, found in the case of DCM radiolysis (under $\mathrm{N}_{2}$ or $\mathrm{O}_{2}$ ), is fortuitously the same as that calculated in the case of water radiolysis (under $\mathrm{N}_{2} \mathrm{O}$ ). Fortunately, this coincidence will enable us to use the same irradiation dose (36 kGy) for all the samples irrespective of the monomer content, solvent and atmosphere.

\subsection{Solvent elimination}

After irradiation, aqueous solutions were centrifuged at a speed of $3 \times 10^{3} \mathrm{rpm}$ for 25 minutes in order to get powdered or gluelike polymers. Differently, after irradiation, in the case of DCM solutions, organic solvents were evaporated by using a rotary evaporator. All the extracted homopolymers and copolymers 
were then dried in an oven for 24 hours at $60{ }^{\circ} \mathrm{C}$. The dried polymer powders were then processed according to the need for different characterization techniques.

\subsection{Characterization methods}

2.5.1. UV-Vis absorption spectroscopy. An HP 8543 spectrophotometer was used to check the UV-Vis absorption properties of monomers before irradiation and of polymers synthesized by radiolysis either in water or in DCM solvent. A quartz cell of $0.2 \mathrm{~cm}$ optical path length was used for absorption measurements. A pure solvent (water or DCM) was systematically used as a reference.

2.5.2. Size exclusion chromatography (SEC). The average molecular weight and chain length of the radiosynthesized homopolymers and copolymers were checked by using SEC chromatography. For this purpose, after solvent elimination, the dried radiosynthesized polymers were dissolved in THF solvent at a concentration of $3 \mathrm{mg} \mathrm{mL} \mathrm{m}^{-1}$ and kept stirring overnight. $100 \mu \mathrm{L}$ of the soluble part of each THF solution was then injected into an SEC apparatus. Using THF as an eluent, SEC was performed at $40{ }^{\circ} \mathrm{C}$ using a Malvern Viscotek TDA apparatus equipped with two columns, Malvern T3000 and T6000, with a Malvern refractive index detector at an elution rate of $1 \mathrm{~mL} \mathrm{~min}^{-1}$. Polystyrene polymers were used as standards to calculate the molecular weights of the radiosynthesized homopolymers and copolymers.

Note that $\mathrm{PPy}_{\mathrm{H}_{2} \mathrm{O}}, \mathrm{PPy}_{\mathrm{DCM}}$ and $\mathrm{PPy} / \mathrm{PEDOT}_{\mathrm{DCM}}$ polymer powders were found to be poorly soluble in THF. As a consequence, it was not possible to determine their average molecular weights, nor their chain lengths, by SEC chromatography.

2.5.3. Attenuated total reflectance Fourier transform infrared (ATR-FTIR) spectroscopy. The chemical composition of all the radiosynthesized homopolymers and copolymers was studied using ATR-FTIR spectroscopy. After solvent elimination, the processed and dried polymers were deposited on the diamond substrate of the FTIR device. The spectra were recorded by using a Bruker Vertex 70 FTIR spectrophotometer with a liquid nitrogen cooling system. Scanning was conducted from 4000 to $600 \mathrm{~cm}^{-1}$ with a $4 \mathrm{~cm}^{-1}$ spectral resolution 100 times and averaged for each spectrum.

2.5.4. Thermogravimetric analysis (TGA). After solvent elimination, the thermal stability and composition analyses of the dried homopolymers and copolymers were performed using a thermogravimetric analysis instrument TGA Q500 (TA Instruments, USA) under a nitrogen flow of $50 \mathrm{~mL} \mathrm{~min}{ }^{-1}$. For this analysis, few milligrams of each sample were used. The temperature was increased from 25 to $800{ }^{\circ} \mathrm{C}$ at a heating rate of $10{ }^{\circ} \mathrm{C} \mathrm{min}^{-1}$.

2.5.5. Scanning electron microscopy (SEM) and energy dispersive X-ray spectroscopy (EDX). In order to investigate the structure and morphology of the radiosynthesized homopolymers and copolymers after deposition, the dried polymer powders, obtained after solvent elimination, were sprinkled onto carbon tapes adhered to aluminium mounts and then coated with gold in order to obtain high resolution images.
SEM observations were performed by using an EVO MA 10 ZEISS microscope. The applied voltage was $15 \mathrm{kV}$. In situ EDX spectroscopy was carried out (without gold coating) in order to identify the chemical composition of each homopolymer and each copolymer with the aim of performing elemental analysis within the selected areas of each sample.

2.5.6. Cryogenic transmission electron microscopy (Cryo-TEM). In order to check the morphology of the homopolymers and copolymers still dispersed after gamma-irradiation in their aqueous or DCM environments, TEM microscopy was used under a cryogenic environment (Cryo-TEM). A drop of each irradiated solution was deposited on holey-carbon-coated grids and quench-frozen by being quickly plunged into liquid ethane. Observations were carried out using a transmission electron microscope LaB6 JEOL JEM 2100 (JEOL, Japan) operated at $200 \mathrm{kV}$.

2.5.7. Electrical conductivity measurements by a four-point probe technique. A four-point probe technique was used to measure the conductivities of the radiosynthesized homopolymers and copolymers. For this purpose, after solvent elimination, the dried radiosynthesized polymer powders were dispersed in THF solvent at a concentration of $10 \mathrm{mg} \mathrm{mL}^{-1}$ and then doped by adding $\mathrm{NOBF}_{4}$ (dissolved in acetonitrile at a concentration of $20 \mathrm{mM}$ ) as a chemical dopant. The doping level was checked by observing the UV-Vis absorption spectra of all the homopolymers and copolymers and the $\mathrm{NOBF}_{4}$ dopant was added consequently until the highest doping level was achieved. Furthermore, $100 \mu \mathrm{L}$ of each highly doped polymer sample was spin-coated on a clean glass substrate at a speed of $1000 \mathrm{rpm}$ for $60 \mathrm{~s}$ and then at $2000 \mathrm{rpm}$ for $30 \mathrm{~s}$. Finally, after drying the samples, the thickness of the obtained polymer films was measured using a 3 Veeco Dektak 150 surface profiler, while their resistance was determined by a Kelvin four-point probe technique. Their conductivity was then calculated by using the following formula:

$$
\rho=\frac{1}{\left(\frac{\pi}{\ln 2} \times \frac{V}{I} \times t\right)}
$$

where $\rho$ is the conductivity $\left(\mathrm{S} \mathrm{cm}^{-1}\right), V$ is the voltage difference, $I$ is the applied current and $t$ is the film thickness $(\mathrm{cm})$.

2.5.8. Cyclic voltammetry (CV). Cyclic voltammetry was used in order to investigate the electrochemical properties and to determine the electronic band gaps of all the radiosynthesized homopolymers and copolymers. The electrochemical setup was a three-electrode cell made of a carbon disk as the working electrode, an Au wire as the counter electrode and an Ag wire as the pseudo-reference electrode. As recommended by IUPAC, calibration of the pseudo-reference electrode was ensured by probing ferrocenium/ferrocene $\left(\mathrm{Fc}^{+} / \mathrm{Fc}\right)$ redox potential at the end of each experiment. After solvent elimination, the dried radiosynthesized polymer powders were dispersed in THF solvent at a concentration of $5 \mathrm{mg} \mathrm{mL}{ }^{-1}$. Then, $100 \mu \mathrm{L}$ of each solution was mixed into the electrochemical cell with $5 \mathrm{~mL}$ of acetonitrile solution containing tetrabutylammonium perchlorate $\left(\mathrm{TBAClO}_{4}\right)$ used as an electrolyte at a concentration of $0.1 \mathrm{M}$. The three electrodes were then immersed into the electrochemical cell and 
the cyclic voltammograms were recorded at a scan rate of $100 \mathrm{mV} \mathrm{s}^{-1}$ between -2.0 and $+2.0 \mathrm{~V}$.

\section{Results and discussion}

As already said, the present work will mainly focus on the experimental results obtained with PPy/PTAA copolymers radiosynthesized in water and DCM solvent. We will evidently compare these results with those obtained with the corresponding PPy and PTAA homopolymers on the one hand and with the other radiosynthesized copolymers, namely, PPy/ PEDOT and PPy/P3HT, on the other hand. Note that for completeness of information, all needed findings which specifically concern PPy/PEDOT and PPy/P3HT copolymers, as well as their corresponding PEDOT and P3HT homopolymers, are given in the ESI. $\dagger$

\subsection{Spectral analysis of monomers}

Systematically, before gamma-irradiation, the UV-Vis absorption spectra of all the monomer solutions were recorded. The absorption spectra of Py, TAA and a mixture of Py and TAA monomers in water $\left(\mathrm{Py}_{\mathrm{H}_{2} \mathrm{O}}, \mathrm{TAA}_{\mathrm{H}_{2} \mathrm{O}}\right.$ and $\left.\mathrm{Py} / \mathrm{TAA}_{\mathrm{H}_{2} \mathrm{O}}\right)$ are displayed in Fig. 1a, while those in DCM ( Py $_{\mathrm{DCM}}, \mathrm{TAA}_{\mathrm{DCM}}$ and Py/TAA $\left.\mathrm{DCM}\right)$ are shown in Fig. 1b. Note that the spectra of the rest of the monomers $\left(\mathrm{EDOT}_{\mathrm{H}_{2} \mathrm{O}}, \mathrm{EDOT}_{\mathrm{DCM}}\right.$ and $3 \mathrm{HT}_{\mathrm{DCM}}$ ) and mixtures of monomers (Py/EDOT $\mathrm{H}_{2} \mathrm{O}, \mathrm{Py} /$ $\mathrm{EDOT}_{\mathrm{DCM}}$ and $\mathrm{Py} / 3 \mathrm{HT}_{\mathrm{DCM}}$ ) are all available in the $\mathrm{ESI}^{\dagger}$ (see Fig. SI1a to SI1c).

All the monomer spectra, in both water and DCM solvents, display absorption bands in the range of 205-260 $\mathrm{nm}$ which are the characteristic peaks of Py and thiophene derivatives and usually ascribed to $\pi-\pi^{*}$ transitions. These observations are in very good agreement with the literature. ${ }^{19,23-26,34,35}$ The study of the variation of each monomer absorption as a function of monomer concentration in water or in DCM (results not shown) enabled us to determine the molar extinction coefficient values at the absorption maxima (of all monomers in both solvents) by using Beer-Lambert's law (see Table SI2 in the ESI $\dagger$ ).

Clearly, the spectra of monomer mixtures $\left(\mathrm{Py} / \mathrm{TAA}_{\mathrm{H}_{2} \mathrm{O}}\right.$ and $\mathrm{Py} / \mathrm{TAA}_{\mathrm{DCM}}$ ) display the characteristic peaks of both monomers and fit well with the arithmetic averages of monomer spectra $\left(\mathrm{Py}_{\mathrm{H}_{2} \mathrm{O}}\right.$ and $\mathrm{TAA}_{\mathrm{H}_{2} \mathrm{O}}$ on the one hand and $\mathrm{Py}_{\mathrm{DCM}}$ and TAA $\mathrm{DCM}_{\mathrm{C}}$ on the other hand) (see Fig. 1a and b). The same observations can be done when considering the other aqueous and DCM solutions (see Fig. SI1a to SI1c in the ESI $\dagger$ ). This additivity of the spectra proves the efficient and homogeneous solubilization of all the monomers and co-monomers in both water and DCM solvents.

\subsection{Radiolytic synthesis of conducting copolymers}

After degassing and sealing in glass ampoules, all the monomer solutions (with or without co-monomers) were irradiated at $36 \mathrm{kGy}$. The aim was to synthesize by radiolysis not only homopolymers in water or DCM $\left(\mathrm{PPy}_{\mathrm{H}_{2} \mathrm{O}}, \mathrm{PTAA}_{\mathrm{H}_{2} \mathrm{O}}, \mathrm{PEDOT}_{\mathrm{H}_{2} \mathrm{O}}, \mathrm{PPy}_{\mathrm{DCM}}, \mathrm{PTAA}_{\mathrm{DCM}}\right.$, PEDOT $_{\text {DCM }}$ and $\left.\mathrm{P} \mathrm{HT}_{\mathrm{DCM}}\right)$, but also copolymers in both solvents (PPy/PTAA $\mathrm{H}_{2} \mathrm{O}, \mathrm{PPy} / \mathrm{PEDOT}_{\mathrm{H}_{2} \mathrm{O}}, \mathrm{PPy} / \mathrm{PTAA}_{\mathrm{DCM}}, \mathrm{PPy} / \mathrm{PED}-$ $\mathrm{OT}_{\mathrm{DCM}}$ and PPy/P3HT

The UV-Vis absorption spectra of $\mathrm{PPy}_{\mathrm{H}_{2} \mathrm{O}}$ and $\mathrm{PTAA}_{\mathrm{H}_{2} \mathrm{O}}$ homopolymers are displayed in Fig. 1c together with the spectrum of PPy/PTAA $\mathrm{H}_{2} \mathrm{O}$ copolymers. Besides, the absorption spectra of $\mathrm{PPy}_{\mathrm{DCM}}$ and $\mathrm{PTAA}_{\mathrm{DCM}}$ homopolymers are displayed in Fig. 1d together with the spectrum of PPy/PTAA ${ }_{\mathrm{DCM}}$ copolymers. Note that the spectra of the rest of the radiosynthesized homopolymers $\left(\mathrm{PEDOT}_{\mathrm{H}_{2} \mathrm{O}}, \mathrm{PEDOT}_{\mathrm{DCM}}\right.$ and $\left.\mathrm{P}_{\mathrm{H}} \mathrm{HT}_{\mathrm{DCM}}\right)$ and copolymers (PPy/PEDOT $\mathrm{H}_{2} \mathrm{O}, \mathrm{PPy} / \mathrm{PEDOT}_{\mathrm{DCM}}$ and PPy/P3HT $\mathrm{DCM}_{\mathrm{DC}}$ ) are all available in the ESI $\dagger$ (see Fig. SI1d to SI1f, ESI $\dagger$ ).

The change in UV-Vis absorption spectra of all the solutions upon irradiation and the colored suspensions obtained after gamma-radiolysis (see the photographs in the inset of Fig. 1c, d, and Fig. SI1d-SI1f, ESI $\dagger$ ) are indicative of the successful synthesis in water and DCM not only of homopolymers, but also of copolymers.

The UV-Vis absorption spectra of $\mathrm{PPy}_{\mathrm{H}_{2} \mathrm{O}}$ and $\mathrm{PTAA}_{\mathrm{H}_{2} \mathrm{O}}$ homopolymers observed in Fig. 1c are in good agreement with our previous studies. ${ }^{19,23-25}$ They display absorption bands in the range of $350-400 \mathrm{~nm}$ which are attributed to the formation of conducting polymers and ascribed to the $\pi-\pi^{*}$ transitions along the polymer chains. Besides, as observed in Fig. 1c, the spectrum of $\mathrm{PPy} / \mathrm{PTAA}_{\mathrm{H}_{2} \mathrm{O}}$ is rather different from the $\mathrm{PPy}_{\mathrm{H}_{2} \mathrm{O}}$ and PTAA $_{\mathrm{H}_{2} \mathrm{O}}$ spectra. This spectrum displays new characteristic absorption peaks at $420 \mathrm{~nm}$ and $620 \mathrm{~nm}$, which are not observed in the homopolymer spectra. Clearly, the PPy/PTAA $\mathrm{H}_{2} \mathrm{O}$ spectrum does not correspond to the overlapping of homopolymer spectra and does not fit with their arithmetic average. This means that the irradiated $\mathrm{Py} / \mathrm{TAA}_{\mathrm{H}_{2} \mathrm{O}}$ aqueous solution does not contain a mixture of homopolymers. As it will be further demonstrated, the $\mathrm{PPy} / \mathrm{PTAA}_{\mathrm{H}_{2} \mathrm{O}}$ solution contains copolymers made of a mixture of Py and TAA monomer units. Note that the red-shifted absorption of PPy/PTAA $\mathrm{H}_{2} \mathrm{O}$ indicates that the copolymer chains are longer than those of homopolymers.

In agreement with our previous studies, the UV-Vis absorption spectra of РРУ $_{\mathrm{DCM}}$ and $\mathrm{PTAA}_{\mathrm{DCM}}$ homopolymers, synthesized in DCM solvent (Fig. 1d), are different from those of $\mathrm{PPy}_{\mathrm{H}_{2} \mathrm{O}}$ and PTAA $_{\mathrm{H}_{2} \mathrm{O}}$ obtained in water. ${ }^{23-25}$ PPy $_{\mathrm{DCM}}$ and PTAA $\mathrm{DCM}_{\mathrm{D}}$ have a maximum absorption peak at around $480 \mathrm{~nm}$ in addition to broad peaks at higher wavelengths in the range of 600-1000 nm, which correspond to polaron and bi-polaron bands, originating from the oxidized state of doped polymers. Indeed, as highlighted in previous studies, dichloromethane radiolysis generates chloride ions which enable in situ production of doped polymers. ${ }^{23-25}$ As a consequence, $\mathrm{PP}_{\mathrm{DCM}}$ and $\mathrm{PTAA}_{\mathrm{DCM}}$ homopolymers are produced doped with chloride ions. This will be further demonstrated. Besides, as observed in Fig. 1d, the spectrum of PPy/PTAA $\mathrm{DCM}_{\mathrm{DCM}}$ does not correspond to the overlapping of $\mathrm{PP}_{\mathrm{DCM}}$ and $\mathrm{PTAA}_{\mathrm{DCM}}$ spectra. This once again means that the irradiated Py/TAA $\mathrm{DCM}_{\mathrm{D}}$ dichloromethane solution does not contain a mixture of homopolymers. It indeed contains copolymers made of a mixture of Py and TAA monomer units. Due to the additional broad peak at a high wavelength, the PPy/PTAA ${ }_{\mathrm{DCM}}$ copolymer synthesized by DCM radiolysis is also found to be doped. 
When considering the other irradiated aqueous and DCM solutions, one can easily note that the UV-Vis absorption spectra of $\mathrm{PPy} / \mathrm{PEDOT}_{\mathrm{H}_{2} \mathrm{O}}, \mathrm{PPy} / \mathrm{PEDOT}_{\mathrm{DCM}}$ and $\mathrm{PPy} / \mathrm{P} 3 \mathrm{HT}_{\mathrm{DCM}}$ do not correspond to the overlapping of the absorption bands of the corresponding homopolymers (see Fig. SI1d-SI1f, ESI $\dagger$ ). This proves that $\mathrm{PPy} / \mathrm{PEDOT}_{\mathrm{H}_{2} \mathrm{O}}, \mathrm{PPy} / \mathrm{PEDOT}_{\mathrm{DCM}}$ and PPy/ $\mathrm{P}_{3} \mathrm{HT}_{\mathrm{DCM}}$ are not a mixture of homopolymers; they all result from efficient copolymerization. Moreover, the presence of additional bands in the range of $600-1000 \mathrm{~nm}$ in the case of

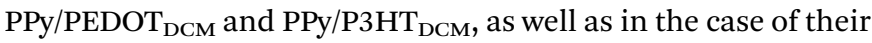
corresponding homopolymers (see Fig. SI1e and SI1f, ESI $\dagger$ ), proves that, contrary to the homopolymers and copolymers produced in water (such as PPy/PEDOT $\mathrm{H}_{2} \mathrm{O}$ ) (see Fig. SI1d, ESI $\dagger$ ), the polymers which are synthesized in DCM are all produced doped.

Successfully, irrespective of the monomer content, solvent and atmosphere, radiolysis of a mixture of two monomers leads to the production of copolymers, which are systematically found to be doped (with chloride ions) when synthesized in DCM solvent.

\subsection{Molecular weight determination}

To estimate the average molecular weight $\left(M_{\mathrm{w}}\right)$ and the chain length of the radiosynthesized homopolymers and copolymers, SEC was performed on the polymer powders which were dissolved in THF after solvent elimination. Note that $\mathrm{PPy}_{\mathrm{H}_{2} \mathrm{O}}, \mathrm{PPy}_{\mathrm{DCM}}$ and $\mathrm{PPy}_{\mathrm{PEDOT}} \mathrm{DCM}_{\mathrm{P}}$ were found to be poorly soluble in THF solvent, probably due to the strong hydrogen bond interactions which pre-exist between the polymer chains, within the polymer powders, avoiding their disassembly. As a consequence, it was not possible to determine the molecular weight of $\mathrm{PPy}_{\mathrm{H}_{2} \mathrm{O}}, \mathrm{PPy}_{\mathrm{DCM}}$ and $\mathrm{PPy} / \mathrm{PEDOT}_{\mathrm{DCM}}$, nor their chain lengths, under the used experimental conditions.

SEC chromatograms obtained in the case of $\mathrm{PPy} / \mathrm{PTAA}_{\mathrm{H}_{2} \mathrm{O}}$ and $\mathrm{PPy} / \mathrm{PTAA}_{\mathrm{DCM}}$ copolymers are shown in the ESI $\dagger$ (Fig. SI2). As highlighted in the inserted table of Fig. SI2 (ESI $\dagger$ ), the weight average molecular weights, obtained with polystyrene calibration, amount respectively to 3103 and $2165 \mathrm{~g} \mathrm{~mol}^{-1}$. These molar masses correspond, in the case of PPy/PTAA $\mathrm{H}_{2} \mathrm{O}$ and PPy/PTAA copolymers, to about 15 and 10 monomer units, respectively, per polymer chain. Note that at this stage of the work, the ratio between the Py $\left(67 \mathrm{~g} \mathrm{~mol}^{-1}\right)$ and TAA $\left(142 \mathrm{~g} \mathrm{~mol}^{-1}\right)$ co-monomer units within a polymer chain is unknown. Nevertheless, for chain length calculation, we supposed a quasi-equimolar content. This will be later justified.

Comparable weight average molecular weights and chain lengths ( 9 and 11 units, respectively) were also obtained in the case of the other THF-soluble PPy/PEDOT $\mathrm{H}_{2} \mathrm{O}$ and PPy/P3HT $\mathrm{HCM}_{\mathrm{DCM}}$ copolymers as deduced from the chromatograms of Fig. SI3a and SI3b (ESI $\dagger)$. The relatively low degree of polymerization found for all the copolymers $\left(\mathrm{PPy} / \mathrm{PTAA}_{\mathrm{H}_{2} \mathrm{O}}, \mathrm{PPy} / \mathrm{PTAA}_{\mathrm{DCM}}\right.$, $\mathrm{PPy} / \mathrm{PEDOT}_{\mathrm{H}_{2} \mathrm{O}}$ and $\mathrm{PPy} / \mathrm{P} 3 \mathrm{HT}_{\mathrm{DCM}}$ ) is not surprising since comparable chain lengths were already reported in the literature in the case of radiosynthesized CPs. ${ }^{23-25}$ Nevertheless, one can also detect from the chromatograms of Fig. SI2 and SI3 (ESI $\dagger$ ) the presence of polymers with much higher molecular weights.
Table 1 Average molecular weights and chain lengths as deduced from SEC chromatography together with degrading temperatures as determined by TGA analysis of all the radiosynthesized homopolymers and copolymers (at 36 kGy). Note that the number of units is the number of monomers in a homopolymer or in a copolymer chain (see Scheme 1)

\begin{tabular}{|c|c|c|c|}
\hline Polymers & $M_{\mathrm{w}}\left(\mathrm{g} \mathrm{mol}^{-1}\right)$ & $\begin{array}{l}\text { Number of } \\
\text { units }\end{array}$ & $\begin{array}{l}\text { Degrading } \\
\text { temperature }\left({ }^{\circ} \mathrm{C}\right)\end{array}$ \\
\hline $\mathrm{PPy}_{\mathrm{H}_{2} \mathrm{O}}$ & Poorly soluble & - & 260 \\
\hline $\mathrm{PPy}_{\mathrm{DCM}}$ & Poorly soluble & - & 160 \\
\hline PTAA $_{\mathrm{H}_{2} \mathrm{O}}$ & 1710 & 12 & 130 \\
\hline PTAA $_{\mathrm{DCM}}$ & 1860 & 13 & 120 \\
\hline PEDOT $_{\mathrm{H}_{2} \mathrm{O}}$ & 2630 & 18 & 140 \\
\hline PEDOT $_{\text {DCM }}$ & 1308 & 9 & 118 \\
\hline $\mathrm{P} 3 \mathrm{HT}_{\mathrm{DCM}}$ & 3042 & 18 & 155 \\
\hline PPy/PTAA $\mathrm{H}_{2} \mathrm{O}$ & 3103 & 15 & 180 \\
\hline PPy/PTAA & 2165 & 10 & 150 \\
\hline $\mathrm{PPy} / \mathrm{PEDOT}_{\mathrm{H}_{2} \mathrm{O}}$ & 1816 & 9 & 180 \\
\hline $\mathrm{PPy} / \mathrm{PEDOT} \mathrm{DCM}$ & Poorly soluble & - & 140 \\
\hline $\mathrm{PPy} / \mathrm{P} 3 \mathrm{HT}_{\mathrm{DCM}}$ & 2592 & 11 & 160 \\
\hline
\end{tabular}

The average molecular weights $\left(M_{\mathrm{w}}\right)$ as well as the chain lengths (number of units) of all the radiosynthesized copolymers are summarized in Table 1 together with the data values corresponding to all the homopolymers radiosynthesized in the present work. As deduced from the $M_{\mathrm{w}}$ values, the chain lengths of all the homopolymers and copolymers are found to comprise between 9 and 18 monomer units per polymer chain. These findings highlight the fact that radiation chemistry mainly leads to the production of CP oligomers, even if much longer polymers are also detected by SEC chromatography.

SEC chromatography enabled the successful determination of homopolymer and copolymer chain lengths, which is an important achievement for promoting the processability of radiosynthesized CPs in various applications. Nevertheless, since all the homopolymer and copolymer chain lengths were found to be comparable (between 9 and 18 units), one can suppose that neither the chemical nature of the monomers (eventually in the presence of co-monomers) nor the nature of the environment (water or DCM as well as atmosphere) has a clear influence on the degree of polymerization of the conducting polymers which are produced by water or dichloromethane radiolysis.

\subsection{Study of chemical composition}

To check the chemical composition of the radiosynthesized homopolymers and copolymers, ATR-FTIR spectroscopy was performed on the polymer powders obtained after solvent elimination. The spectra of homopolymers were compared with those of pure monomers, while the spectra of copolymers were compared with those of monomer mixtures.

The FTIR spectra of pure Py, pure TAA and a mixture of Py and TAA (Py + TAA) monomers are displayed twice in Fig. 2a and $b$ for clarity. Note that the spectra of the rest of the monomers (EDOT and 3HT) and of the rest of the monomer mixtures (Py + EDOT and Py + 3HT) are all available in the ESI $\dagger$ (see Fig. SI4a to SI4c, ESI $\dagger$ ). As observed in all these figures, the resolution of spectra of monomers and of monomer mixtures is 
higher than that of the homopolymer and copolymer spectra. Indeed, while the monomers are characterized by ATR-FTIR spectroscopy in the liquid phase (pure monomers), the polymers are analyzed in the solid phase (polymer powders).

All the ATR-FTIR spectra of the monomers are in very good agreement with previous studies in which the different peaks were already ascribed. ${ }^{19,23-26,34,35}$ Clearly and logically, as observed in Fig. 2, the FTIR spectrum of the monomer mixture (Py + TAA) displays the characteristic peaks of both Py and TAA monomers. Naturally, the same observation can be done when considering the FTIR spectra of the other monomer mixtures $(\mathrm{Py}+$ EDOT and Py $+3 \mathrm{HT}$ ) (see Fig. SI 4 in the ESI $\dagger$ ) which result from the combination of pure monomer spectra.

The FTIR spectra of $\mathrm{PPy}_{\mathrm{H}_{2} \mathrm{O}}$ and $\mathrm{PTAA}_{\mathrm{H}_{2} \mathrm{O}}$ homopolymers are displayed in Fig. 2a together with the spectrum of PPy/PTAA $\mathrm{H}_{2} \mathrm{O}$ copolymers. Besides, the FTIR spectra of PPy $_{\mathrm{DCM}}$ and PTAA $\mathrm{DCM}_{\mathrm{D}}$ homopolymers are displayed in Fig. $2 \mathrm{~b}$ together with the spectrum of $\mathrm{PPy} / \mathrm{PTAA}_{\mathrm{DCM}}$ copolymers. Note that the infrared spectra of the rest of the radiosynthesized homopolymers (PEDOT $_{\mathrm{H}_{2} \mathrm{O}}, \mathrm{PEDOT}_{\mathrm{DCM}}$ and $\left.\mathrm{P}_{\mathrm{H}} \mathrm{HT}_{\mathrm{DCM}}\right)$ and copolymers (PPy/

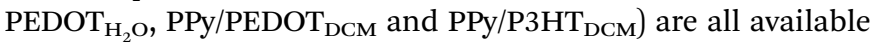
in the ESI $\dagger$ (see Fig. SI4a to SI4c).

The FTIR spectra of PPy, PTAA and P3HT homopolymers obtained in both solvents by water (Fig. 2a and Fig. SI4a, ESI $\dagger$ ) and DCM (Fig. 2b and Fig. SI4b, SI4c, ESI $\dagger$ ) radiolysis are different from those of the corresponding monomers, but are in very good agreement with the conducting polymer spectra described in the literature. ${ }^{19,23-26,34-36}$ Indeed, the peaks observed in the infrared spectra of the homopolymers have already been described and ascribed and undoubtedly highlight, in the present work (such as in the literature), the quantitative consumption of monomers and the successful radiation-induced synthesis of conducting homopolymers.
Let us consider now the infrared spectra of the monomer mixtures and the resulting copolymers (in water and in DCM) and let us describe in more detail the FTIR spectrum of the Py + TAA mixture as well as those of PPy/PTAA ${ }_{\mathrm{H} 2 \mathrm{O}}$ and PPy/PTAA ${ }_{\mathrm{DCM}}$ copolymers. As observed in Fig. 2, the infrared bands of the Py + TAA monomer mixture located at $1417 \mathrm{~cm}^{-1}, 1525 \mathrm{~cm}^{-1}, 1687 \mathrm{~cm}^{-1}$ and $1047 \mathrm{~cm}^{-1}$ are ascribed to the $\mathrm{C}-\mathrm{N}, \mathrm{C}=\mathrm{C}$ and $\mathrm{C}-\mathrm{C}$ stretching vibrations and the $\mathrm{C}-\mathrm{H}$ in-plane deformation bands present in the Py ring, respectively, while the strong band at $734 \mathrm{~cm}^{-1}$ characterizes the $\mathrm{C}-\mathrm{H}$ wag vibration at the $\alpha$ and $\alpha^{\prime}$ positions in the Py monomers. ${ }^{37-39}$ Additionally, the bands between 1300 and $1200 \mathrm{~cm}^{-1}$, at $952 \mathrm{~cm}^{-1}$ and at $835 \mathrm{~cm}^{-1}$ are attributed to the $\mathrm{C}-\mathrm{O}$ bending vibrations belonging to the side chain of the thiophene ring, the $\mathrm{C}-\mathrm{S}$ stretching vibration and the $\beta \mathrm{C}-\mathrm{H}$ out-of-plane deformation bands in the TAA monomer, while the band at $734 \mathrm{~cm}^{-1}$ is also characteristic of the $\mathrm{C}_{\alpha}-\mathrm{H}$ out-of-plane deformation vibration of the thiophene ring in the TAA monomer. ${ }^{40-42}$

When considering the spectra of PPy/PTAA $\mathrm{H}_{2} \mathrm{O}$ and PPy/ PTAA $_{\text {DCM }}$ copolymers, one can observe that almost all the bands which were present in the spectrum of the Py + TAA mixture before irradiation are still present in the polymer spectra, nevertheless with a slight shift and a lower resolution. One can note, for instance, the presence of the band at $3386 \mathrm{~cm}^{-1}$ attributed to the $\mathrm{N}-\mathrm{H}$ stretching in the Py monomer and of the peak at around $1700 \mathrm{~cm}^{-1}$ corresponding to the $\mathrm{C}=\mathrm{O}$ vibration in the TAA monomer.

Interestingly, the band at $734 \mathrm{~cm}^{-1}$, which is characteristic of $\mathrm{C}_{\alpha}-\mathrm{H}$ vibrations in both Py and TAA monomers and which is remarkable in the monomer spectra (and a fortiori in the Py + TAA mixture spectrum), appears barely noticeable in the spectra of PPy/PTAA $\mathrm{H}_{2} \mathrm{O}$ and PPy/PTAA ${ }_{\mathrm{DCM}}$ copolymers. This finding confirms the quantitative and concomitant polymerization of
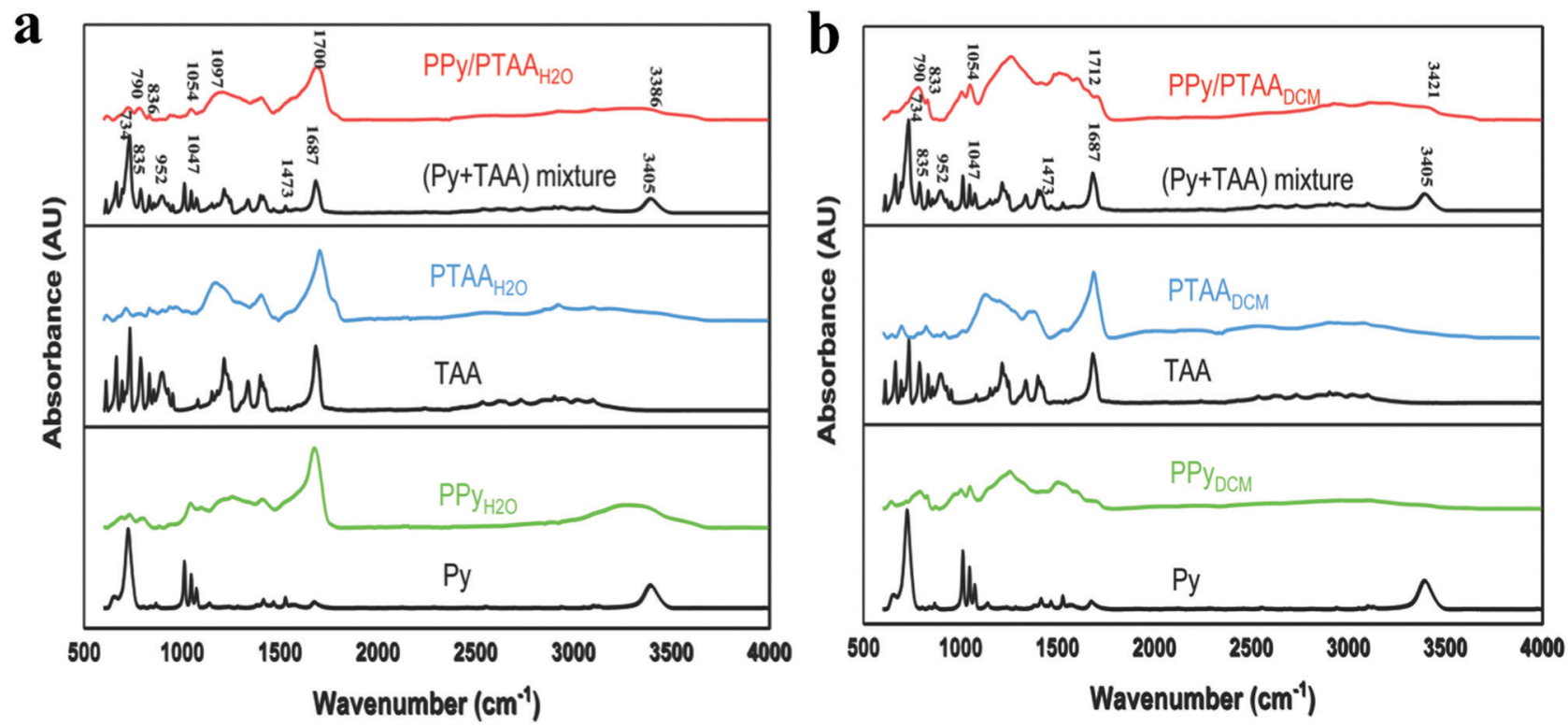

Fig. 2 ATR-FTIR spectra of (a) PPy $\mathrm{H}_{2} \mathrm{O}$, PTAA $\mathrm{H}_{2} \mathrm{O}$ and PPy/PTAA $\mathrm{H}_{2} \mathrm{O}$ polymers prepared in water at 36 kGy, (b) PPy polymers prepared in dichloromethane (DCM) solution at $36 \mathrm{kGy}$. The spectra of pure Py, pure TAA and Py + TAA mixture are presented twice for clarity. 
both Py and TAA monomers, through $\alpha-\alpha^{\prime}$ coupling reactions (according to Scheme 1), by water and DCM radiolysis.

When considering the infrared spectra of the rest of the copolymers, namely, PPy/PEDOT $\mathrm{H}_{2} \mathrm{O}, \mathrm{PPy}_{\mathrm{PEDOT}} \mathrm{PCM}_{\mathrm{P}}$ and $\mathrm{PPy} / \mathrm{P} 3 \mathrm{HT}_{\mathrm{DCM}}$, one can find in each of them the peaks of the corresponding monomers (even if slightly shifted) (Fig. SI4, ESI $\dagger$ ). Significantly, in each case, the peak characterizing $\mathrm{C}_{\alpha}-\mathrm{H}$ bonds in the monomers disappears upon gamma-irradiation, highlighting in all the cases the quantitative radiation-induced polymerization of all the monomers.

In all the cases and irrespective of the starting monomers, solvent and atmosphere, the ATR-FTIR spectroscopy highlighted the successful and quantitative synthesis of copolymers through $\alpha-\alpha^{\prime}$ coupling reactions, according to Scheme 1 .

\subsection{Thermal stability analysis}

Thermogravimetric analysis (TGA) was used in order to check and compare the thermal behavior and thermo-degradability of the homopolymers and copolymers produced by gamma-radiolysis. The polymer powders obtained after solvent elimination were used in all cases.

The TGA thermograms of $\mathrm{PPy}_{\mathrm{H}_{2} \mathrm{O}}$ and $\mathrm{PTAA}_{\mathrm{H}_{2} \mathrm{O}}$ homopolymers are displayed in Fig. 3a together with the thermogram of PPy/ PTAA $_{\mathrm{H}_{2} \mathrm{O}}$ copolymers. Besides, the TGA thermograms of PPy $\mathrm{DCM}_{\mathrm{DCM}}$ and PTAA $_{\mathrm{DCM}}$ homopolymers are displayed in Fig. 3b together with that of PPy/PTAA ${ }_{\mathrm{DCM}}$ copolymers. Note that the thermograms of the rest of the radiosynthesized homopolymers $\left(\mathrm{PEDOT}_{\mathrm{H}_{2} \mathrm{O}}\right.$, PEDOT $_{\mathrm{DCM}}$ and $\mathrm{P}_{3} \mathrm{HT}_{\mathrm{DCM}}$ ) and copolymers (PPy/PEDOT $\mathrm{H}_{2} \mathrm{O}, \mathrm{PPy} /$ $\mathrm{PEDOT}_{\mathrm{DCM}}$ and $\left.\mathrm{PPy} / \mathrm{P} \mathrm{HT}_{\mathrm{DCM}}\right)$ are all available in the $\mathrm{ESI} \dagger$ (see Fig. SI5a to SI5c). All the TGA curves of homopolymers found in the present work are in very good agreement with previous studies. ${ }^{19,23-25}$ Importantly, the degrading temperatures of all the homopolymers and copolymers radiosynthesized in this work are listed in Table 1.

As observed in Fig. 3a, the thermogram of PPy/PTAA $\mathrm{H}_{2} \mathrm{O}$ is rather different from the $\mathrm{PPy}_{\mathrm{H}_{2} \mathrm{O}}$ and $\mathrm{PTAA}_{\mathrm{H}_{2} \mathrm{O}}$ thermograms. The first step weight loss of $\mathrm{PPy}_{\mathrm{H}_{2} \mathrm{O}}$ is about $12 \%$, which is higher than that of $\mathrm{PTAA}_{\mathrm{H}_{2} \mathrm{O}}(3 \%)$ and $\mathrm{PPy} \mathrm{PTAA}_{\mathrm{H}_{2} \mathrm{O}}(6 \%)$. For these samples, the initial weight loss can be explained by water evaporation while the greater weight loss of $\mathrm{PPy}_{\mathrm{H}_{2} \mathrm{O}}$ can be explained by its increased hygroscopic nature. ${ }^{19,23-25}$ After water evaporation, $\mathrm{PPy}_{\mathrm{H}_{2} \mathrm{O}}$ and $\mathrm{PTAA}_{\mathrm{H}_{2} \mathrm{O}}$ homopolymers remain stable till $260{ }^{\circ} \mathrm{C}$ and $130{ }^{\circ} \mathrm{C}$, respectively. Interestingly, the PPy/ PTAA $_{\mathrm{H}_{2} \mathrm{O}}$ thermal degradation is not characterized by the two successive degrading temperatures $\left(130{ }^{\circ} \mathrm{C}\right.$ then $\left.260{ }^{\circ} \mathrm{C}\right)$. On the contrary, $\mathrm{PPy} / \mathrm{PTAA}_{\mathrm{H}_{2} \mathrm{O}}$ is characterized by a single intermediate degrading temperature of $180{ }^{\circ} \mathrm{C}$ (Fig. 3a and Table 1) highlighting its copolymer nature. Above these degrading temperatures, the decomposition plots of $\mathrm{PPy}_{\mathrm{H}_{2} \mathrm{O}}, \mathrm{PTAA}_{\mathrm{H}_{2} \mathrm{O}}$ and $\mathrm{PPy} / \mathrm{PTAA}_{\mathrm{H}_{2} \mathrm{O}}$ appear different. The successive stages of decomposition observed in the different plots should correspond to the progressive degradation of polymers according to their molecular weights. Polymers with the greatest molecular weights remain stable up to $800{ }^{\circ} \mathrm{C}$. At this temperature, the plots clearly show that the total weight loss of PPy/PTAA $\mathrm{H}_{2} \mathrm{O}(60 \%)$ is relatively less than that of $\mathrm{PPy}_{\mathrm{H}_{2} \mathrm{O}}(100 \%)$ and $\mathrm{PTAA}_{\mathrm{H}_{2} \mathrm{O}}(90 \%)$ indicating the greater thermal stability of $\mathrm{PPy} / \mathrm{PTAA}_{\mathrm{H}_{2} \mathrm{O}}$ at high temperatures. This enhanced thermal stability of copolymers can be explained by the longer chain lengths of $\mathrm{PPy} / \mathrm{PTAA}_{\mathrm{H}_{2} \mathrm{O}}$ copolymers as compared with those of the corresponding $\mathrm{PPy}_{\mathrm{H}_{2} \mathrm{O}}$ and $\mathrm{PTAA}_{\mathrm{H}_{2} \mathrm{O}}$ homopolymers as found by SEC chromatography and as indicated in Table 1.

When considering the thermograms of $\mathrm{PPy}_{\mathrm{DCM}}, \mathrm{PTAA}_{\mathrm{DCM}}$ and $\mathrm{PPy} / \mathrm{PTAA}_{\mathrm{DCM}}$ displayed in Fig. $3 \mathrm{~b}$, similar observations can be made. Indeed, $\mathrm{PP}_{\mathrm{DCM}}$ and $\mathrm{PTAA}_{\mathrm{DCM}}$ homopolymers remain stable till $160{ }^{\circ} \mathrm{C}$ and $118{ }^{\circ} \mathrm{C}$, respectively, while the PPy/ PTAA $_{\text {DCM }}$ copolymer is characterized by a single intermediate degrading temperature of $150{ }^{\circ} \mathrm{C}$ (Table 1) proving once again the effective copolymerization. Also, above these degrading temperatures, the decomposition plots and thus the weight losses of $\mathrm{PPy}_{\mathrm{DCM}}, \mathrm{PTAA}_{\mathrm{DCM}}$ and $\mathrm{PPy} / \mathrm{PTAA}_{\mathrm{DCM}}$ appear totally different. In particular, the thermal stabilities at high temperatures $\left(800{ }^{\circ} \mathrm{C}\right)$ of $\mathrm{PPy}_{\mathrm{DCM}}, \mathrm{PTAA}_{\mathrm{DCM}}$ and PPy/PTAA ${ }_{\mathrm{DCM}}$ polymers (those with greatest molecular weights) are directly related to their chain
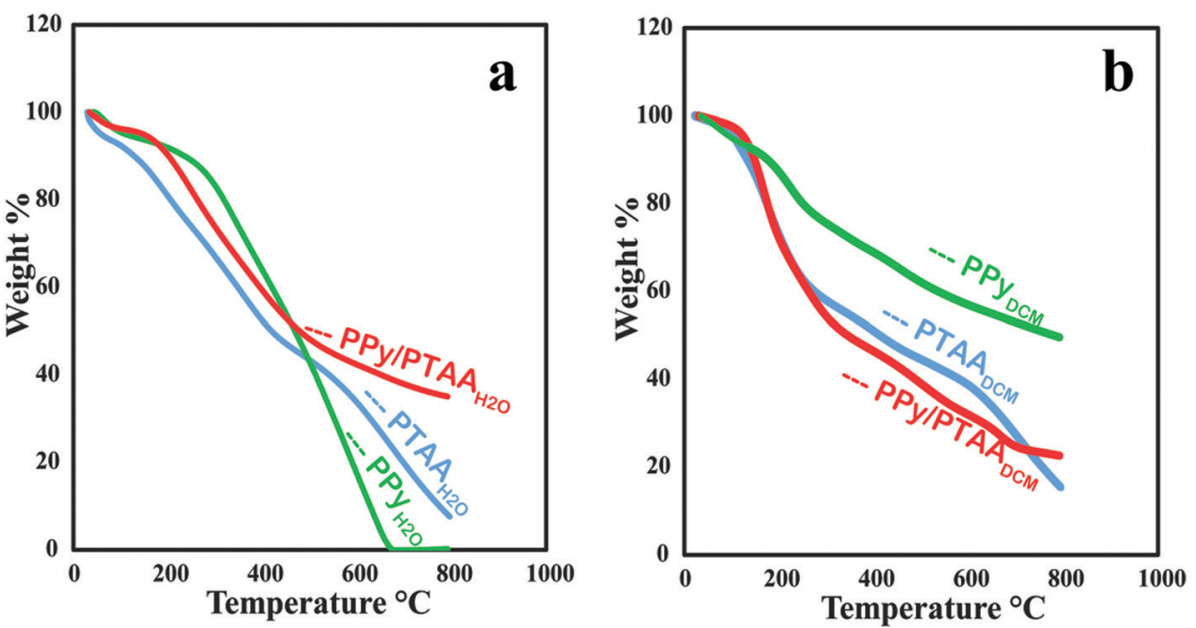

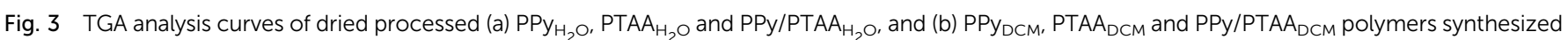
at 36 kGy. 
lengths (values found by SEC chromatography as indicated in Table 1).

When considering the thermograms of the rest of the radiosynthesized copolymers (PPy/PEDOT $\mathrm{H}_{2} \mathrm{O}, \mathrm{PPy} / \mathrm{PEDOT}_{\mathrm{DCM}}$ and $\mathrm{PPy} / \mathrm{P} 3 \mathrm{HT}_{\mathrm{DCM}}$ ) displayed in Fig. SI5 (ESI $\dagger$ ), one can once again note that the degrading temperatures of copolymers are found systematically to be between those of their corresponding homopolymers (see the degrading temperatures in Table 1). Also, the weight losses of copolymers as a function of temperature are different from those of their corresponding homopolymers, the thermal stability at higher temperatures being systematically related to the copolymer and homopolymer chain lengths.

As highlighted by the TGA analysis, the thermal behaviors of the copolymers are clearly different from those of their corresponding homopolymers. The degrading temperatures of copolymers, which are between 140 and $180{ }^{\circ} \mathrm{C}$ as indicated in Table 1 , are systematically found to be between the degrading temperatures of their corresponding homopolymers proving the effective copolymerization of Py monomers and co-monomers. Besides, the thermal stability of copolymers and homopolymers at the highest temperatures looks independent of the chemical content (in terms of monomer units in the presence or in the absence of co-monomers) and seems mainly dependent on the chain length: the longer polymers are characterized by the greater thermal stability. Due to their average molecular weights and their chain lengths, copolymer weight losses are between 60 and $80 \%$ at $800{ }^{\circ} \mathrm{C}$.

\subsection{Structural characterization}

SEM and Cryo-TEM microscopies were used to check the morphologies of the homopolymers and copolymers produced by gamma-radiolysis. Aqueous and DCM suspensions of the polymers were used for Cryo-TEM observations, while the polymer powders, obtained after solvent elimination, were used for SEM characterizations.

The SEM images of $\mathrm{PPy}_{\mathrm{H}_{2} \mathrm{O}}$ and $\mathrm{PTAA}_{\mathrm{H}_{2} \mathrm{O}}$ homopolymers are displayed in Fig. $4 \mathrm{a}$ and $\mathrm{b}$ together with the SEM and Cryo-TEM images of PPy/PTAA $\mathrm{H}_{2} \mathrm{O}$ copolymers (Fig. 4c and g, respectively). Besides, the SEM images of PРy $_{\mathrm{DCM}}$ and PTAA $_{\mathrm{DCM}}$ homopolymers are displayed in Fig. $4 \mathrm{~d}$ and e together with the SEM and Cryo-TEM images of PPy/PTAA ${ }_{\text {DCM }}$ copolymers (Fig. 4f and h, respectively). Note that the SEM photographs of the rest of the radiosynthesized homopolymers $\left(\mathrm{PEDOT}_{\mathrm{H}_{2} \mathrm{O}}, \mathrm{PEDOT}_{\mathrm{DCM}}\right.$ and $\mathrm{P}_{3} \mathrm{HT}_{\mathrm{DCM}}$ ) as well as the SEM and Cryo-TEM images of the rest of the copolymers (PPy/PEDOT $\mathrm{H}_{2} \mathrm{O}$, PPy/PEDOT $_{\mathrm{DCM}}$ and PPy/ $\mathrm{P}_{3} \mathrm{HT}_{\mathrm{DCM}}$ ) are all available in the ESI $\dagger$ (Fig. SI6). The SEM and Cryo-TEM images obtained in this work are in good agreement with previous studies which concerned homopolymers. ${ }^{19,23-25}$ Indeed, all the images highlight the presence of more or less packed polymer nanoparticles, heterogeneous in size, knowing that each nanoparticle corresponds to the self-assembly (thanks to hydrogen bonds or van der Waals interactions) of independent amorphous polymer chains. As previously explained, depending on their hydrophilic functionalities, polymer nanoparticles either efficiently dissolve in water or DCM or, on the contrary, selfassemble leading to close-packed aggregated particles. According to the SEM and Cryo-TEM observations, the morphologies and mean sizes of the homopolymers and copolymers synthesized in this work are summarized in Table SI3 (ESI $\dagger$ ).

The SEM image of $\mathrm{PPy}_{\mathrm{H}_{2} \mathrm{O}}$ homopolymers (Fig. 4a) shows the presence of spherical nanostructures with diameters between 150 and $250 \mathrm{~nm}$, while that of PTAA $_{\mathrm{H}_{2} \mathrm{O}}$ homopolymers (Fig. 4b) highlights the presence of bigger spherical particles with diameters in the range of 200-700 $\mathrm{nm}$. In contrast with the
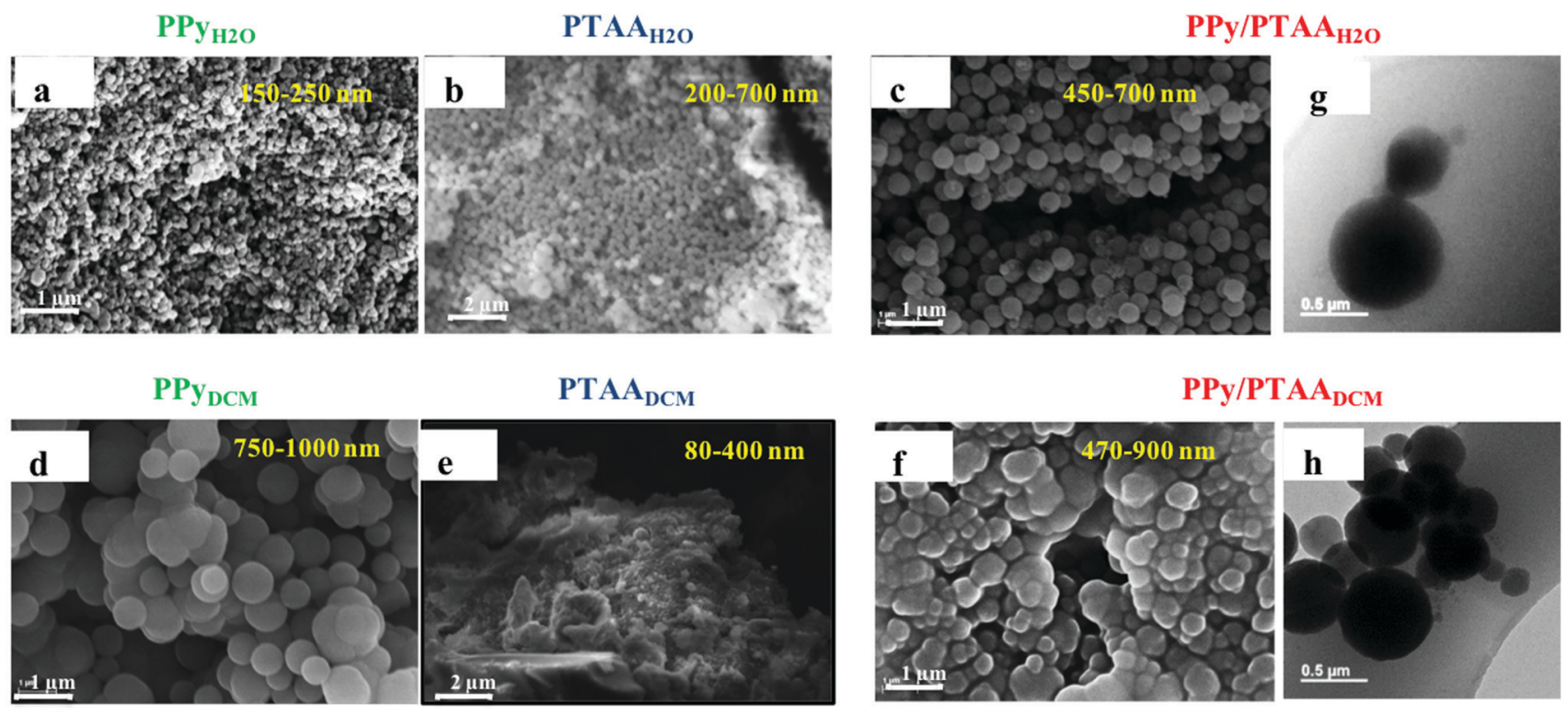

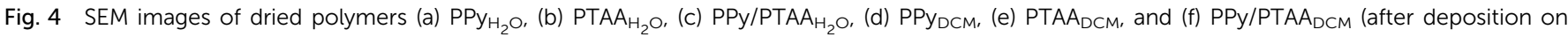
carbon tapes adhered to aluminium mounts with gold coating) together with the Cryo-TEM images of (g) PPy/PTAA $\mathrm{H}_{2} \mathrm{O}$ and (h) PPy/PTAA were obtained after irradiation at 36 kGy. 
corresponding homopolymers, PPy/PTAA $\mathrm{H}_{2} \mathrm{O}$ copolymers (Fig. 4c) appear as bigger spherical nanostructures with main sizes in the range of 450-700 $\mathrm{nm}$. The morphology (shape and size) and polydispersity of PPy/PTAA $\mathrm{H}_{2} \mathrm{O}$ copolymer nanoparticles are confirmed by the Cryo-TEM observations as shown in Fig. $4 \mathrm{~g}$, confirming that neither the deposition onto the solid substrate nor the drying procedure has an influence on the morphology of copolymers.

When considering the polymers radiosynthesized in DCM, one can observe a different morphology. Indeed, $Р$ Pу $_{\mathrm{DCM}}$ homopolymers (Fig. 4d) appear as clusters of "huge" nanoparticles, the diameters of which remain between 750 and $1000 \mathrm{~nm}$. PTAA $_{\text {DCM }}$ homopolymers (Fig. 4e) appear as granular clusters of some micrometers, consisting of close-packed spherical nanogranules of $80-150 \mathrm{~nm}$ in diameter. Such granular clusters were observed in the whole sample indicating that PTAA $_{\mathrm{DCM}}$ nanoparticles are aggregated in DCM solvent and not isolated as in the case of water. In contrast with the corresponding homopolymers, PPy/PTAA ${ }_{\text {DCM }}$ copolymers (Fig. 4f) appear as more or less aggregated spheroidal particles, with intermediate sizes in the range of 470-900 $\mathrm{nm}$ (in between the mean sizes of $\mathrm{PPy}_{\mathrm{DCM}}$ and $\mathrm{PTAA}_{\mathrm{DCM}}$ homopolymers). Interestingly, the morphology and the packing of PPy/PTAA ${ }_{\mathrm{DCM}}$ copolymer nanoparticles are confirmed by the Cryo-TEM observations as shown in Fig. $4 \mathrm{~h}$.

When considering the SEM and Cryo-TEM images of the rest of the radiosynthesized copolymers $\left(\mathrm{PPy} / \mathrm{PEDOT}_{\mathrm{H}_{2} \mathrm{O}}, \mathrm{PPy} / \mathrm{PEDOT}_{\mathrm{DCM}}\right.$ and $\mathrm{PPy} / \mathrm{P} 3 \mathrm{HT}_{\mathrm{DCM}}$ ) displayed in Fig. SI6 (ESI $\dagger$ ), one can once again note that the morphology, mean size and packing of copolymer nanoparticles differ from those of the corresponding homopolymers as specified in Table SI3 (ESI $\dagger$ ). The change in the morphology and packing is evidently the proof of the co-incorporation of Py units together with the thiophene derivative monomers into the backbone of copolymer chains.

During SEM observations, in order to identify the chemical composition of all the radiosynthesized homopolymers and copolymers and to perform their elemental analysis in different areas of the samples, in situ energy-dispersive X-ray spectroscopy (EDX) analysis was systematically carried out (results not shown).

While the EDX analysis of $\mathrm{PPy}_{\mathrm{H}_{2} \mathrm{O}}$ and $\mathrm{PPy}_{\mathrm{DCM}}$ homopolymers highlighted the presence of $\mathrm{N}$ atoms in both samples (in addition to $\mathrm{C}$ atoms), the EDX analysis of homopolymers made of thiophene derivatives $\left(\mathrm{PTAA}_{\mathrm{H}_{2} \mathrm{O}}, \mathrm{PTAA}_{\mathrm{DCM}}, \mathrm{PEDOT}_{\mathrm{H}_{2} \mathrm{O}}\right.$, $\mathrm{PEDOT}_{\mathrm{DCM}}$ and $\mathrm{P}_{3} \mathrm{HT}_{\mathrm{DCM}}$ ) revealed the presence of $\mathrm{S}$ atoms (in addition to $\mathrm{C}$ and $\mathrm{O}$ atoms, except in the case of P3HT where $\mathrm{O}$ element was evidently absent). These results are in good agreement with the chemical compositions of the used monomers (see Scheme 1) and lead to the following ascertainment: within the radiosynthesized polymers, the presence of nitrogen is the specific signature of Py units, while the presence of sulfur is indicative of thiophene derivative units (TAA, EDOT or 3HT).

The EDX analysis of PPy/PTAA $\mathrm{H}_{2} \mathrm{O}, \mathrm{PPy} / \mathrm{PTAA}_{\mathrm{DCM}}, \mathrm{PPy} / \mathrm{PEDOT}_{\mathrm{H}_{2} \mathrm{O}}$,

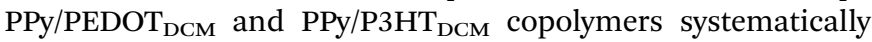
highlighted for each sample, irrespective of the analyzed area, the concomitant presence of both nitrogen and sulfur elements.
This important result definitely demonstrates the presence of two kinds of monomer units (Py monomers together with comonomers) in each sample, validating the effective copolymerization (see Scheme 1). A quantitative analysis enabled us to estimate the $\mathrm{S}$ and $\mathrm{N}$ atomic percentages in different areas of each copolymer sample and thus to evaluate the molar ratio between both atoms in each sample. Excitingly, in all the copolymer samples, the ratio of sulfur-to-nitrogen was found to be approximately 1 (ratios between 0.9 and 1.1), which indicates that each radiosynthesized copolymer is made of a quasi-stoichiometric mixture of Py units and thiophene derivative co-monomers. This is in total agreement with the experimental conditions since an equimolar mixture of the monomers was systematically used for copolymer synthesis ( $5 \mathrm{mM}$ Py and $5 \mathrm{mM}$ co-monomer (TAA, EDOT or 3HT)). This result also confirms the fact that all the monomers are oxidized and polymerized with the same yield as expected.

Interestingly, the EDX analysis of the homopolymers and copolymers radiosynthesized in DCM solvent enabled the systematic detection of chlorine $(\mathrm{Cl})$ atoms in all the analyzed areas of the samples. This observation definitely proves that PPy/PTAA ${ }_{\text {DCM }}$, PPy/PEDOT ${ }_{\mathrm{DCM}}$ and $\mathrm{PPy} / \mathrm{P} 3 \mathrm{HT}_{\mathrm{DCM}}$ copolymers are doped with chloride ions, as expected from DCM radiolysis, and in total agreement with the UV-Vis absorption spectroscopy analysis.

As highlighted by the SEM and Cryo-TEM microscopies, all the radiosynthesized copolymers appear as spherical nanoparticles (with diameters of several hundreds of $\mathrm{nm}$ ), the size and packing of which differ from those of the corresponding homopolymers. Irrefutably, the EDX analysis demonstrates the successful radiation-induced copolymerization of Py and thiophene derivative monomers and their presence in stoichiometric proportions within the backbone of each copolymer. Moreover, the EDX analysis highlights the specific doping state of copolymers produced by DCM radiolysis.

\subsection{Conductivity measurements and band gap calculations}

A four-point probe technique was used to measure the electrical conductivities of the radiosynthesized homopolymers and copolymers. All the measurements were performed on the polymer powders which were first dissolved in THF after solvent elimination, then chemically doped and finally coated on glass substrates.

The average electrical conductivities found in the present work in the case of all radiosynthesized materials are summarized in Table 2. The conductivity values of all the homopolymers and copolymers are found to be in agreement with previous results concerning radiosynthesized homopolymers available in the literature. ${ }^{19,23-25}$ These conductivities appear relatively high when compared with the relatively low molecular weights of polymers. As observed, electrical conductivities are of the same order of magnitude. Only the $\mathrm{PPy}_{\mathrm{H}_{2} \mathrm{O}}$ conductivity is more than ten times greater than all the other conductivities. Contrary to what might be expected, conductivities obtained under the present experimental conditions do not seem to be dependent on the polymer chain lengths (see Table 1). Surprisingly, while 
homopolymers and copolymers synthesized in DCM are systematically in situ doped with chloride ions after radiolysis, their conductivities, as measured by the four-point probe technique, are not significantly greater than those of the undoped polymers produced by water radiolysis.

Now, when comparing the conductivities of copolymers with those of the corresponding homopolymers, one can find that the electrical conductivities of copolymers are systematically found to be between the conductivities of the corresponding homopolymers proving the effective copolymerization of Py monomers together with co-monomers. For instance, the PPy/ PTAA $_{\mathrm{H}_{2} \mathrm{O}}$ conductivity (which amounts to $0.9 \times 10^{-3} \mathrm{~S} \mathrm{~cm}^{-1}$ ) is between the $\mathrm{PPy}_{\mathrm{H}_{2} \mathrm{O}}$ conductivity $\left(57 \times 10^{-3} \mathrm{~S} \mathrm{~cm}^{-1}\right)$ and the PTAA $_{\mathrm{H}_{2} \mathrm{O}}$ conductivity $\left(0.6 \times 10^{-3} \mathrm{~S} \mathrm{~cm}^{-1}\right)$. Similarly, the PPy/ PTAA $_{\text {DCM }}$ conductivity (which amounts to $2.8 \times 10^{-3} \mathrm{~S} \mathrm{~cm}^{-1}$ ) is between the $\mathrm{PPy}_{\mathrm{DCM}}$ conductivity $\left(3.4 \times 10^{-3} \mathrm{~S} \mathrm{~cm}^{-1}\right)$ and the PTAA $_{\text {DCM }}$ conductivity $\left(1.6 \times 10^{-3} \mathrm{~S} \mathrm{~cm}^{-1}\right)$.

The optical band gaps of the radiosynthesized homopolymers and copolymers can be deduced from Tauc plots which can be easily read out from the UV-Vis absorption spectra of the different materials. In order to draw on Tauc plots for all the homopolymers and copolymers, we considered the absorption spectra of the radiosynthesized polymer powders dissolved in THF solvent (after water or DCM elimination). The UV-Vis absorption spectra of PPy/PTAA $\mathrm{H}_{2} \mathrm{O}$ and PPy/PTAA ${ }_{\text {DCM }}$ in THF are displayed in the inset of Fig. 5, while the spectra of PPy/ PEDOT $_{\mathrm{H}_{2} \mathrm{O}}, \mathrm{PPy}_{\mathrm{PEDOT}_{\mathrm{DCM}}}$ and PPy/P3HT $\mathrm{DCM}_{\mathrm{D}}$ dissolved in THF are shown in the inset of Fig. SI7 (available in the ESI $\dagger$ ).

In the context of Tauc plots, based on the Tauc equation (eqn (8)) applied to amorphous materials, such as radiosynthesized conducting polymers, $(\alpha h \nu)^{1 / 2}$ must be plotted as a function of photon energy $(h \nu)$ according to:

$$
(\alpha h \nu)^{1 / 2}=A\left(h \nu-E_{\mathrm{g}}\right)
$$

where $\alpha, h, \nu$ and $E_{\mathrm{g}}$ are, respectively, the absorption coefficient, Planck constant, light frequency and optical band gap energy. In this equation, $A$ is a constant.

Thus, the optical band gap, $E_{\mathrm{g}}$, of a given material can be determined by extrapolating the straight-line portion of its Tauc plot to the photon energy axis.

The Tauc plots of PPy/PTAA $\mathrm{H}_{2} \mathrm{O}$ and PPy/PTAA ${ }_{\mathrm{DCM}}$ are displayed in Fig. 5, while those of the other copolymers are all available in Fig. SI7 (ESI $\dagger$ ). As observed, plotting $(\alpha h \nu)^{1 / 2}$ as a function of photon energy $(h \nu)$ enabled us to get the optical band gaps of all the copolymers by the intercept of the tangents of the plots to the $x$-axis: while the optical band gap of PPy/ PTAA $_{\mathrm{H}_{2} \mathrm{O}}$ amounts to $1.33 \mathrm{eV}$ (Fig. 5a), that of PPy/PTAA about $1.90 \mathrm{eV}$ (Fig. 5b).

Comparable optical band gap values were obtained in the case of the other PPy/PEDOT $\mathrm{H}_{2} \mathrm{O}, \mathrm{PPy} / \mathrm{PEDOT}_{\mathrm{DCM}}$ and PPy/ $\mathrm{P}_{3} \mathrm{HT}_{\mathrm{DCM}}$ copolymers $(1.80 \mathrm{eV}, 1.74 \mathrm{eV}$ and $1.50 \mathrm{eV}$, respectively) as deduced from their Tauc plots (Fig. SI7a to SI7c, ESI $\dagger$ ).

The optical band gap values $\left(E_{\mathrm{g}}\right)$ of all the copolymers are summarized in Table 2 together with those of all the homopolymers radiosynthesized in the present work, the latter values being in good agreement with previous results on
Table 2 Conductivities, optical band gaps $\left(E_{\mathrm{g}}\right)$ deduced from Tauc plots and $\mathrm{HOMO}$ energy levels obtained from $\mathrm{CV}$ of all homopolymers and copolymers synthesized in this work at $36 \mathrm{kGy}$. LUMO energy levels were calculated by using $E_{\mathrm{g}}$ values and $\mathrm{HOMO}$ energy levels

\begin{tabular}{|c|c|c|c|c|}
\hline Polymer & $\begin{array}{l}\text { Electrical } \\
\text { conductivity } \\
\left(10^{-3} \mathrm{~S} \mathrm{~cm}^{-1}\right) \\
\end{array}$ & $\begin{array}{l}\text { Optical } \\
\text { band } \\
\text { gap }\left(E_{\mathrm{g}}\right)(\mathrm{eV})\end{array}$ & $\begin{array}{l}\text { HOMO } \\
\text { energy } \\
\text { level }(\mathrm{eV})\end{array}$ & $\begin{array}{l}\text { LUMO } \\
\text { energy level } \\
\left(E_{\mathrm{g}}+\text { HOMO }\right)(\mathrm{eV})\end{array}$ \\
\hline $\mathrm{PPy}_{\mathrm{H}_{2} \mathrm{O}}$ & 57 & 2.00 & - & - \\
\hline PPy $_{\text {DCM }}$ & 3.4 & 2.00 & - & - \\
\hline PTAA $_{\mathrm{H}_{2} \mathrm{O}}$ & 0.6 & 2.40 & -6.24 & -3.84 \\
\hline PTAA $_{\text {DCM }}$ & 1.6 & 1.40 & -6.15 & -4.75 \\
\hline $\operatorname{PEDOT}_{\mathrm{H}_{2} \mathrm{O}}$ & 3.3 & 1.70 & -5.55 & -3.85 \\
\hline $\mathrm{PEDOT}_{\mathrm{DCM}}$ & 2.6 & 1.80 & -5.45 & -3.65 \\
\hline $\mathrm{P} 3 \mathrm{HT}_{\mathrm{DCM}}$ & 0.7 & 1.60 & -5.87 & -4.27 \\
\hline $\mathrm{PPy} / \mathrm{PTAA}_{\mathrm{H}_{2} \mathrm{O}}$ & 0.9 & 1.33 & -5.83 & -4.50 \\
\hline $\mathrm{PPy} / \mathrm{PTAA}_{\mathrm{DCM}}$ & 2.8 & 1.90 & -6.22 & -4.32 \\
\hline $\mathrm{PPy} / \mathrm{PEDOT}_{\mathrm{H}_{2} \mathrm{O}}$ & 4.7 & 1.80 & -5.93 & -4.13 \\
\hline PPy/ & 2.0 & 1.74 & -5.70 & -3.96 \\
\hline \multicolumn{5}{|l|}{ PEDOT $_{\text {DCM }}$} \\
\hline $\mathrm{PPy} / \mathrm{P} 3 \mathrm{HT}_{\mathrm{DCM}}$ & 1.0 & 1.50 & -6.30 & -4.80 \\
\hline
\end{tabular}

radiosynthesized homopolymers available in the literature. ${ }^{23-25}$ As observed, all the optical band gaps are of the same order of magnitude in the range of $1.33-2.00 \mathrm{eV}$ and remain relatively low. As for conductivities, the optical band gaps obtained under the present experimental conditions do not seem to be dependent on the polymer chain lengths (see Table 1 ) nor on the doping state of the polymers (by chlorine ions), since the optical band gaps of the polymers synthesized in DCM are not systematically lower than those of the undoped polymers which are produced by water radiolysis.

Now, when comparing the optical band gaps of the copolymers with those of their corresponding homopolymers (Table 2), one can find that the optical band gap values of the copolymers are most often between those of their corresponding homopolymers and are even sometimes lower, proving once again the effective copolymerization of Py monomers together with thiophene derivatives.

Cyclic voltammetry was used in order to investigate the electrochemical properties of all the radiosynthesized homopolymers and copolymers. All the measurements were performed on the radiosynthesized polymer powders which were first dissolved in THF after solvent elimination, and then mixed into the electrochemical cell with acetonitrile solution containing tetrabutylammonium perchlorate $\left(\mathrm{TBAClO}_{4}\right)$ used as an electrolyte. Note that due to the poor solubility of $\mathrm{PPy}_{\mathrm{H}_{2} \mathrm{O}}$ and $\mathrm{PPy}_{\mathrm{DCM}}$ homopolymers, it was not possible to record their voltammograms under the used experimental conditions.

The cyclic voltammograms (CVs) of PPy/PTAA $\mathrm{H}_{2} \mathrm{O}$ and PPy/ PTAA $_{\text {DCM }}$ are displayed in Fig. 6, while those of PPy/PEDOT $\mathrm{H}_{2} \mathrm{O}$, $\mathrm{PPy}_{\mathrm{PEDOT}} \mathrm{DCM}_{\mathrm{PC}}$ and PPy/P3HT ${ }_{\mathrm{DCM}}$ are shown in Fig. SI8 (ESI $\dagger$ ). The study of all CVs enabled the determination of oxidation potentials, $E_{\mathrm{ox}}$, of all the copolymers. The CV profiles of PPy/ $\mathrm{PTAA}_{\mathrm{H}_{2} \mathrm{O}}$ and $\mathrm{PPy} / \mathrm{P} 3 \mathrm{HT}_{\mathrm{DCM}}$ show that p-doping (oxidation) processes occur at the onset potentials of $+1.56 \mathrm{~V}$ (Fig. 6a) and $+1.95 \mathrm{~V}$ (Fig. 6b), respectively. In the same way, the oxidation potentials of the rest of the copolymers, namely, $\mathrm{PPy} / \mathrm{PEDOT}_{\mathrm{H}_{2} \mathrm{O}}, \mathrm{PPy} / \mathrm{PEDOT}_{\mathrm{DCM}}$ and $\mathrm{PPy} / \mathrm{P} 3 \mathrm{HT}_{\mathrm{DCM}}$, are deduced 

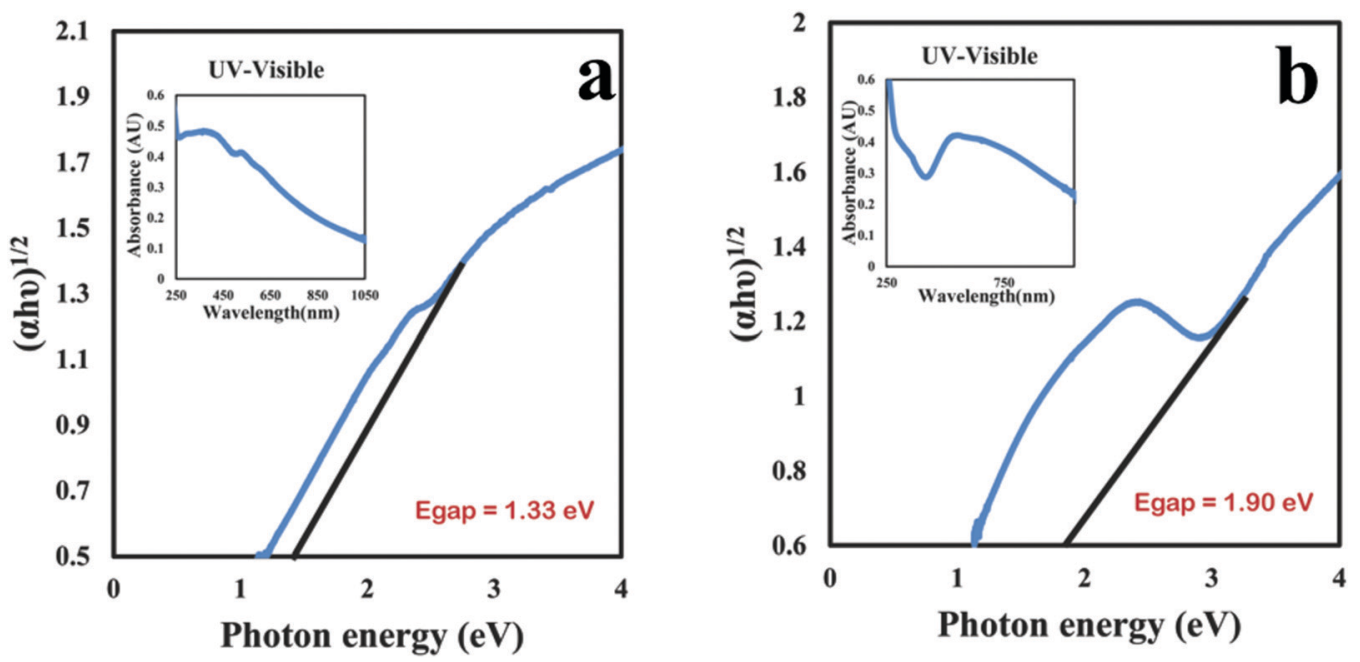

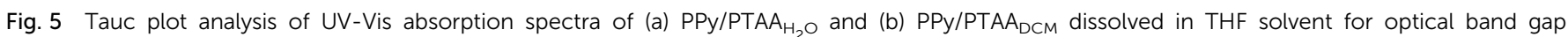
assessment. Insets: UV-Vis absorption spectra of respective polymers in THF. The optical path length was $0.2 \mathrm{~cm}$ and the reference was pure THF solvent.

from their cyclic voltammograms and amount to $+1.66 \mathrm{~V},+1.43 \mathrm{~V}$ and $+2.03 \mathrm{~V}$, respectively (Fig. SI8a to SI8c, ESI $\dagger$ ). Interestingly, the presence of a single oxidation peak in each $\mathrm{CV}$ is an undeniable proof that there is not a mixture of homopolymers and that copolymerization was successful in all cases.

Usually, by using the equation given in the caption of Fig. 6, starting from the oxidation potential, $E_{\mathrm{Ox}}$, of a given material, one can calculate the energy level, $E_{\text {Hомо, of }}$ its highest occupied molecular orbital (HOMO). The $E_{\text {Hомо }}$ energy levels of all the radiosynthesized copolymers were thus calculated by using the ferrocene ionization potential value as standard. For instance, the HOMO energy levels found for $\mathrm{PPy} / \mathrm{PTAA}_{\mathrm{H} 2 \mathrm{O}}$ and PPy/PTAA ${ }_{\mathrm{DCM}}$ amount to $-5.83 \mathrm{eV}$ and $-6.22 \mathrm{eV}$, respectively. Note that the corrected value of $4.8 \mathrm{eV} v s$. vacuum of ferrocene, which is widely adopted, is based on the calculation obtained by Pommerehne et al. ${ }^{43}$

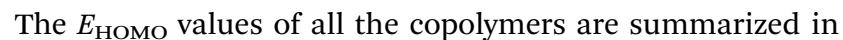
Table 2 together with those of all the corresponding homopolymers which were radiosynthesized in the present work (except $\mathrm{PPy}_{\mathrm{H}_{2} \mathrm{O}}$ and $\mathrm{PPy}_{\mathrm{DCM}}$ ). Note that the values found here in the case of homopolymers are in good agreement with previous studies. ${ }^{23-25}$

The study of cyclic voltammograms which led to the determination of oxidation potentials of polymers did not enable the determination of their reduction potentials, $E_{\text {red }}$, nor the energy levels, $E_{\text {Lumo, of their lowest unoccupied }}$ molecular orbitals (LUMO). As a consequence, the determination of electronic band gaps of the radiosynthesized homopolymers and copolymers was not directly possible from the electrochemical measurements. Nevertheless, for each polymer, the knowledge of its optical band gap $\left(E_{\mathrm{g}}\right)$ and its HOMO energy level ( $\left.E_{\text {HOMO }}\right)$ makes it possible to indirectly calculate $E_{\text {LUMO }}$ according
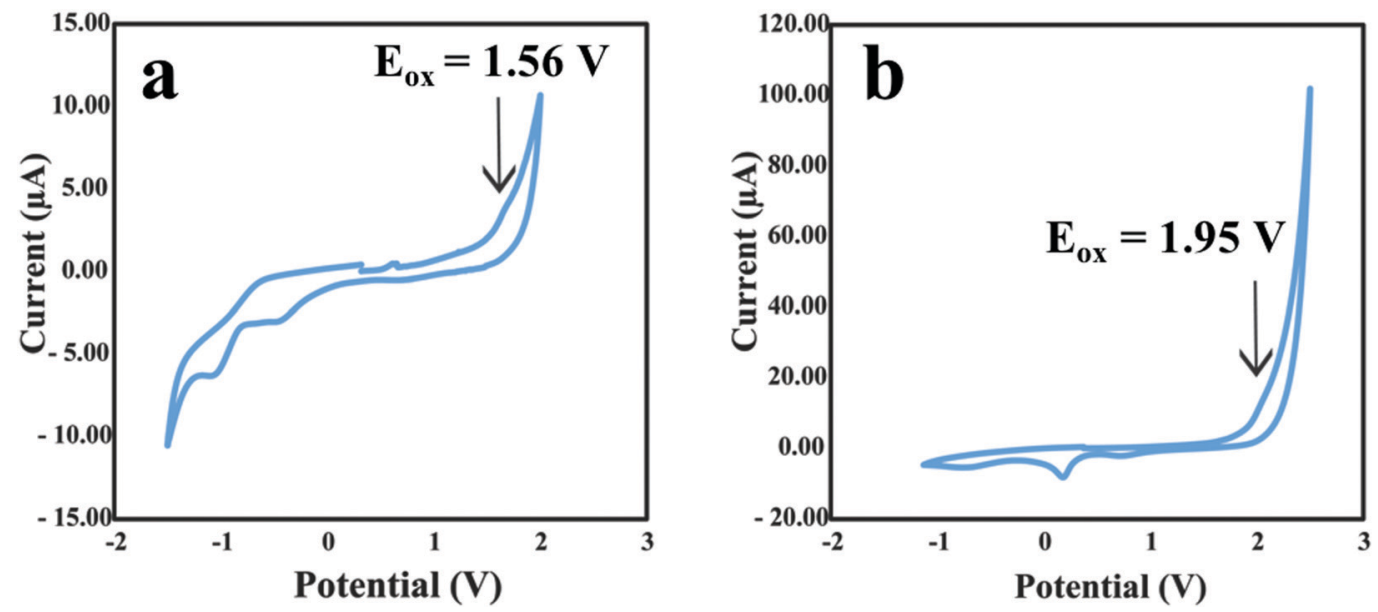

Fig. 6 Cyclic voltammograms of (a) PPy/PTAA $\mathrm{H}_{2} \mathrm{O}$ and (b) PPy/PTAA $\mathrm{DCM}_{\text {dissolved in } \mathrm{THF} \text { and recorded in acetonitrile containing } 0.1 \mathrm{M} \text { TBAClO }}$ at a scan rate of $100 \mathrm{mV} \mathrm{s}^{-1}$. The polymers were synthesized at $36 \mathrm{kGy}$ either in water or in $\mathrm{DCM}$. The redox potential of ferrocenium/ferrocene $(\mathrm{Fc} / \mathrm{Fc})$ was measured to calibrate the pseudo-reference electrode $(0.53 \mathrm{~V}$ vs. the pseudo-reference electrode used in the present study). The HOMO energy levels of polymers were calculated from oxidation potentials as follows: $E_{\mathrm{HOMO}}(\mathrm{eV})=-4.80-e\left(E_{\mathrm{ox}}-0.53\right)$, where $e$ is the elementary charge. 
to: $E_{\mathrm{g}}=E_{\mathrm{LUMO}}-E_{\mathrm{HOMO}}$. The $E_{\mathrm{LuMO}}$ energy levels of all the radiosynthesized copolymers were thus calculated in this way. For instance, the LUMO energy levels of PPy/PTAA $\mathrm{H}_{2} \mathrm{O}$ and PPy/ $\mathrm{PTAA}_{\mathrm{DCM}}$ are, respectively, found to be $-4.50 \mathrm{eV}$ and $-4.32 \mathrm{eV}$.

The $E_{\text {LUMO }}$ values of all the copolymers and homopolymers synthesized in the present work are summarized in Table 2 (except for $\mathrm{PPy}_{\mathrm{H}_{2} \mathrm{O}}$ and $\mathrm{PPy}_{\mathrm{DCM}}$ ) together with the $E_{\mathrm{HOMO}}$ and optical band gap values. Note that the $E_{\mathrm{LUMO}}$ values found here in the case of homopolymers are in good agreement with previous studies. $^{23-25}$

It is not easy to comment on the influence of the chain length or the effect of the doping by chlorine ions on the HOMO and LUMO energy levels of the radiosynthesized polymers. Besides, it is not possible to correctly compare the $E_{\mathrm{HOMO}}$ and $E_{\mathrm{LUMO}}$ values of the copolymers with those of their corresponding homopolymers since data related to $\mathrm{PPy}_{\mathrm{H}_{2} \mathrm{O}}$ and $\mathrm{PPy}_{\mathrm{DCM}}$ are lacking. Nevertheless, the change in the electrochemical behavior of the copolymers with respect to PTAA, PEDOT and P3HT homopolymers successfully validates the copolymerization.

The obtained results from the electrical conductivity measurements, cyclic voltammetry experiments and optical band gap calculations confirm the successful radiation-induced copolymerization. Interestingly, the electrical conductivities and optical band gap values of the radiosynthesized copolymers are found to be between those of their corresponding homopolymers. Now, importantly, the range of values found for both HOMO and LUMO energy levels is promising and favorable for the use of copolymers in practical applications, such as in solar cells.

\section{Conclusion}

In this work, starting from an equimolar mixture of Py and a thiophene derivative as a co-monomer, PPy/PTAA, PPy/PEDOT and PPy/P3HT copolymers are successfully synthesized in both water and DCM solvents together with all their respective homopolymers (PPy, PTAA, PEDOT and P3HT) for comparative purposes. ATR-FTIR spectroscopy and cyclic voltammetry highlight the successful and quantitative synthesis of copolymers through $\alpha-\alpha^{\prime}$ coupling reactions, while the EDX analysis demonstrates the presence of both Py and co-monomer in stoichiometric proportions within the backbone of all copolymers. Contrary to copolymers synthesized in aqueous solutions which are found to be undoped, those produced in DCM are systematically found to be doped with chloride ions (produced by DCM radiolysis) as highlighted by the EDX and UV-Vis absorption spectroscopies.

Contrary to PPy homopolymers which are poorly soluble (particularly in THF and acetonitrile solvents) and thus only partially processable (preventing their successful characterization by SEC chromatography and cyclic voltammetry for instance), PPy/ PTAA, PPy/PEDOT and PPy/P3HT copolymers are much more soluble and readily processable. This indicates that TAA, EDOT and 3 HT monomer units, incorporated within the materials, help in increasing the solubility of Py copolymers, making their characterization (by a multitude of complementary techniques) possible.
As highlighted by the SEM and Cryo-TEM microscopies, PPy/ PTAA, PPy/PEDOT and PPy/P3HT copolymers, obtained either in water or in DCM, appear as spherical nanoparticles (with mean diameters of several hundreds of $\mathrm{nm}$ ), the size and packing of which differ from those of the corresponding homopolymers. The observed differences in the morphology should come from the more or less strong hydrogen bond interactions (and/or van der Waals interactions) within each particle and between the nanoparticles (depending on the hydrophilicity of the constitutive monomers and comonomers). As demonstrated by the SEC chromatography, the copolymer chain lengths are all of the same order of magnitude and are comparable to those of homopolymers, highlighting the fact that neither the chemical nature of the monomers nor the nature of the environment (water or DCM solvent) has a clear influence on the degree of polymerization.

The physicochemical properties of copolymers, such as UV-Vis absorption spectra (in water, DCM and THF), are found to be different from those of homopolymers, confirming the effective copolymerization. As highlighted by the TGA analysis, the thermal stability of copolymers at high temperatures appears to be mainly dependent on their chain lengths. Besides, the copolymer degrading temperatures (all between 140 and $180{ }^{\circ} \mathrm{C}$ ) are systematically found to be between the degrading temperatures of the corresponding homopolymers. This highlights the fact that Py monomer units, incorporated within the polymer materials, help in increasing the thermal stability of PTAA, PEDOT and P3HT polymers. In the same way, the electrical conductivities (as measured by the four-point probe technique) and optical band gap values (as deduced from the absorption spectra) of copolymers are found to be between those of the corresponding homopolymers. It is worth noting that the incorporation of TAA, EDOT or 3HT monomer units systematically lowers the copolymer band gaps in comparison with the band gaps of PPy homopolymers. Finally, the HOMO and LUMO energy levels of copolymers are found to be different from those of homopolymers.

The obtained results highlight the fact that all the copolymers synthesized by radiolysis (thanks to gamma-sources as in the present work or alternatively by the way of X-ray generators or particle accelerators) constitute promising candidates for different practical applications. Since electron accelerators are becoming increasingly widespread in industry, their use gives a glimpse of future promising industrial applications in the field of conducting polymer synthesis.

One of the major aims is now to enhance the physicochemical properties of radiosynthesized copolymers (thermal stability, conductivity, electroactivity, band gap value), while also improving their processability. This work is thus in due course in order to increase the copolymer chain length by varying the dose rate or by using water/DCM microemulsions (to enhance the yield of polymerization). Also, different monomer ratios will be used in order to adjust the hydrophilicity of radiosynthesized copolymers, control their morphology and tune their properties. 


\section{Author contributions}

Teseer Bahry: conceptualization, software, validation, resources, writing - first draft and visualization. Benazir Khurshid: methodology, software, formal analysis, investigation, resources, and visualization. Yamina Chouli: formal analysis and investigation. Souad Abou Zeid: formal analysis and investigation. Cyrille Sollogoub: validation and investigation (SEM and EDX experiments). Matthieu Gervais: validation and investigation (SEC and TGA experiments). Thanh-Tuân Bui: validation and investigation (CV experiments, conductivity measurements). Fabrice Goubard: validation and investigation (CV experiments, conductivity measurements). Samy Remita: conceptualization, methodology, validation, writing - original draft, writing - review and editing, visualization, supervision, and project administration.

\section{Conflicts of interest}

There are no conflicts to declare. The authors declare that they have no known competing financial interests or personal relationships that could have appeared to influence the work reported in this paper.

\section{Acknowledgements}

We thank Jean-Michel Guignier (IMPMC, Université Pierre et Marie Curie, France) for help in performing Cryo-TEM experiments.

\section{References}

1 A. J. Heeger, J. Phys. Chem. B, 2001, 105, 8475-8491.

2 A. P. H. J. Schenning and E. W. Meijer, in Encyclopedia of Materials: Science and Technology, ed. K. H. J. Buschow, R. W. Cahn, M. C. Flemings, B. Ilschner, E. J. Kramer, S. Mahajan and P. Veyssière, Elsevier, Oxford, 2001, pp. 3400-3407.

3 T. O. Magu, A. U. Agobi, L. Hitler and P. M. Dass, J. Chem. Rev., 2019, 1, 19-34.

4 A. Kausar and M. Siddiq, Polymer Science: Research Advances, Practical Applications and Educational Aspects. Formatex Research Center, 2016, pp. 177-187.

5 L.-X. Wang, X.-G. Li and Y.-L. Yang, React. Funct. Polym., 2001, 47, 125-139.

6 T. y. V. Vernitskaya and O. N. Efimov, Russ. Chem. Rev., 1997, 66, 443-457.

7 J. L. Brédas, J. C. Scott, K. Yakushi and G. B. Street, Phys. Rev. B: Condens. Matter Mater. Phys., 1984, 30, 1023-1025.

8 Z. Zhao-yang, T. Yi-jie, X. Xiao-qian, Z. Yong-jiang, C. Haifeng and Z. Wen-wei, J. Appl. Polym. Sci., 2013, 129(3), 1506-1512.

9 A. F. Diaz, J. Castillo, K. K. Kanazawa, J. A. Logan, M. Salmon and O. Fajardo, J. Electroanal. Chem. Interfacial Electrochem., 1982, 133, 233-239.

10 H. K. Youssoufi, M. Hmyene, F. Garnier and D. Delabouglise, J. Chem. Soc., Chem. Commun., 1993, 1550-1552.
11 G. Zotti, S. Zecchin, G. Schiavon, B. Vercelli, A. Berlin and S. Grimoldi, Macromol. Chem. Phys., 2004, 205, 2026-2031.

12 A. Berlin, G. Zotti, S. Zecchin, G. Schiavon, B. Vercelli and A. Zanelli, Chem. Mater., 2004, 16, 3667-3676.

13 A. Tewari, A. Kokil, S. Ravichandran, S. Nagarajan, R. Bouldin, L. A. Samuelson, R. Nagarajan and J. Kumar, Macromol. Chem. Phys., 2010, 211, 1610-1617.

14 E. Sahmetlioglu, H. Yuruk, L. Toppare, I. Cianga and Y. Yagci, Polym. Int., 2004, 53(12), 2138-2144.

15 Y. Lattach, A. Deniset-Besseau, J.-M. Guigner and S. Remita, Radiat. Phys. Chem., 2013, 82, 44-53.

16 Y. Lattach, C. Coletta, S. Ghosh and S. Remita, ChemPhysChem, 2014, 15, 208-218.

17 I. M. Ward, Contemp. Phys., 2009, 50, 670.

18 C. Coletta, Z. Cui, P. Archirel, P. Pernot, J.-L. Marignier and S. Remita, J. Phys. Chem. B, 2015, 119, 5282-5298.

19 Z. Cui, C. Coletta, A. Dazzi, P. Lefrançois, M. Gervais, S. Néron and S. Remita, Langmuir, 2014, 30, 14086-14094.

20 Z. Cui, T. Bahry, A. Dazzi, T.-T. Bui, F. Goubard and S. Remita, Radiat. Phys. Chem., 2019, 159, 47-56.

21 C. Coletta, Z. Cui, A. Dazzi, J.-M. Guigner, S. Néron, J.-L. Marignier and S. Remita, Radiat. Phys. Chem., 2016, 126, 21-31.

22 Z. Cui, C. Coletta, R. Rebois, S. Baiz, M. Gervais, F. Goubard, P.-H. Aubert, A. Dazzi and S. Remita, Radiat. Phys. Chem., 2016, 119, 157-166.

23 T. Bahry, Z. Cui, A. Deniset-Besseau, M. Gervais, C. Sollogoub, T.-T. Bui and S. Remita, New J. Chem., 2018, 42, 8704-8716.

24 T. Bahry, Z. Cui, A. Deniset-Besseau, M. Gervais, I. Mbomekalle, C. Sollogoub, P.-H. Aubert, T.-T. Bui and S. Remita, New J. Chem., 2020, 44, 11652-11666.

25 T. Bahry, Z. Cui, A. Dazzi, M. Gervais, C. Sollogoub, F. Goubard, T.-T. Bui and S. Remita, Radiat. Phys. Chem., 2021, 180, 109291.

26 X. Yuan, D. Floresyona, P.-H. Aubert, T.-T. Bui, S. Remita, S. Ghosh, F. Brisset, F. Goubard and H. Remita, Appl. Catal., $B, 2019,242,284-292$.

27 J. W. T. Spinks and R. J. Woods, John Wiley \& Sons, Inc., New York, 1990, vol. 3, pp. 251-256.

28 C. Ferradini and J.-P. Jay-Gerin, Res. Chem. Intermed., 2000, 26, 549-565.

29 C. Ferradini and J.-P. Jay-Gerin, Can. J. Chem., 1999, 77, 1542-1575.

30 G. Baldacchino, T. Maeyama, S. Yamashita, M. Taguchi, A. Kimura, Y. Katsumura and T. Murakami, Chem. Phys. Lett., 2009, 468, 275-279.

31 Z. B. Alfassi, S. Mosseri and P. Neta, J. Phys. Chem., 1989, 93, 1380-1385.

32 S. S. Emmi, M. D’Angelantonio, G. Beggiato, G. Poggi, A. Geri, D. Pietropaolo and G. Zotti, Radiat. Phys. Chem., 1999, 54, 263-270.

33 S. S. Emmi, G. Beggiato and G. Casalbore-Miceli, Radiat. Phys. Chem., 1989, 33, 29-37.

34 E. J. Beiting, K. J. Zeringue and R. E. Stickel, Spectrochim. Acta, Part A, 1985, 41, 1413-1418.

35 R. M. Silverstein and G. C. Bassler, J. Chem. Educ., 1962, 39, 546. 
36 T. Wu, L. Wang, Y. Zhang, S. Du, W. Guo and M. Pei, RSC Adv., 2015, 5, 16684-16690.

37 S. Geetha and D. C. Trivedi, Mater. Chem. Phys., 2004, 88, 388-397.

38 C. He, C. Yang and Y. Li, Synth. Met., 2003, 139, 539-545.

39 D. P. Dubal, S. V. Patil, A. D. Jagadale and C. D. Lokhande, J. Alloys Compd., 2011, 509, 8183-8188.

40 C. Wang, J. L. Schindler, C. R. Kannewurf and M. G. Kanatzidis, Chem. Mater., 1995, 7, 58-68.
41 J. Casado, V. Hernández, S. Hotta and J. T. López Navarrete, J. Chem. Phys., 1998, 109, 10419-10429.

42 U. H. Yildiz, E. Sahin, I. M. Akhmedov, C. Tanyeli and L. Toppare, J. Polym. Sci., Part A: Polym. Chem., 2006, 44, 2215-2225.

43 J. Pommerehne, H. Vestweber, W. Guss, R. F. Mahrt, H. Bässler, M. Porsch and J. Daub, Adv. Mater., 1995, 7, 551-554. 